Eastern Illinois University

The Keep

Masters Theses

Student Theses \& Publications

$1-1-2016$

\title{
Stress as a Moderator of Visual Perception: Do Elevated Stress Levels Interfere with Visual Cognition?
}

\author{
Ashley Ebersole \\ Eastern Illinois University \\ This research is a product of the graduate program in Clinical Psychology at Eastern Illinois University. Find \\ out more about the program.
}

\section{Recommended Citation}

Ebersole, Ashley, "Stress as a Moderator of Visual Perception: Do Elevated Stress Levels Interfere with Visual Cognition?" (2016). Masters Theses. 2439.

http://thekeep.eiu.edu/theses/2439

This Thesis is brought to you for free and open access by the Student Theses \& Publications at The Keep. It has been accepted for inclusion in Masters Theses by an authorized administrator of The Keep. For more information, please contact tabruns@eiu.edu. 
Thesis Maintenance and Reproduction Certificate

FOR: $\quad$ Graduate Candidates Completing Theses in Partial Fulfillment of the Degree Graduate Faculty Advisors Directing the Theses

RE: $\quad$ Preservation, Reproduction, and Distribution of Thesis Research

Preserving, reproducing, and distributing thesis research is an important part of Booth Library's responsibility to provide access to scholarship. In order to further this goal, Booth Library makes all graduate theses completed as part of a degree program at Eastern Illinois University available for personal study, research, and other not-for-profit educational purposes. Under 17 U.S.C. § 108, the library may reproduce and distribute a copy without infringing on copyright; however, professional courtesy dictates that permission be requested from the author before doing so.

Your signatures affirm the following:

- The graduate candidate is the author of this thesis.

- The graduate candidate retains the copyright and intellectual property rights associated with the original research, creative activity, and intellectual or artistic content of the thesis.

- The graduate candidate certifies her/his compliance with federal copyright law (Title 17 of the U. S. Code) and her/his right to authorize reproduction and distribution of all copyrighted materials included in this thesis.

- The graduate candidate in consultation with the faculty advisor grants Booth Library the nonexclusive, perpetual right to make copies of the thesis freely and publicly available without restriction, by means of any current or successive technology, including by not limited to photocopying, microfilm, digitization, or internet.

- The graduate candidate acknowledges that by depositing her/his thesis with Booth Library, her/his work is available for viewing by the public and may be borrowed through the library's circulation and interlibrary loan departments, or accessed electronically.

- The graduate candidate waives the confidentiality provisions of the Family Educational Rights and Privacy Act (FERPA) (20 U. S. C. $§ 1232 \mathrm{~g}$; 34 CFR Part 99) with respect to the contents of the thesis and with respect to information concerning authorship of the thesis, including name and status as a student at Eastern Illinois University.

I have conferred with my graduate faculty advisor. My signature below indicates that I have read and agree with the above statements, and hereby give my permission to allow Booth Library to reproduce and distribute my thesis. My adviser's signature indicates concurrence to reproduce and distribute the thesis.

Graduate'Candidate Signature
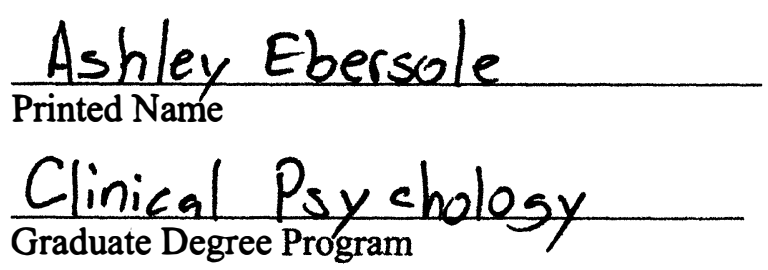
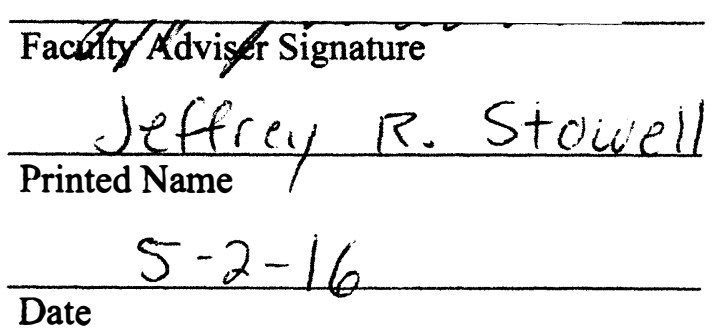

Please submit in duplicate. 
Stress as a Moderator of Visual Perception: Do Elevated

\section{Stress Levels Interfere with Visual Cognition?}

(TITLE)

BY

\section{Ashley Ebersole}

\section{THESIS}

SUBMITTED IN PARTIAL FULFILLMENT OF THE REQUIREMENTS FOR THE DEGREE OF

Master of Arts in Clinical Psychology

IN THE GRADUATE SCHOOL, EASTERN ILLINOIS UNIVERSITY

CHARLESTON, ILLINOIS

2016

YEAR

I HEREBY RECOMMEND THAT THIS THESIS BE ACCEPTED AS FULFILLING THIS PART OF THE GRADUATE DEGREE CITED ABOVE

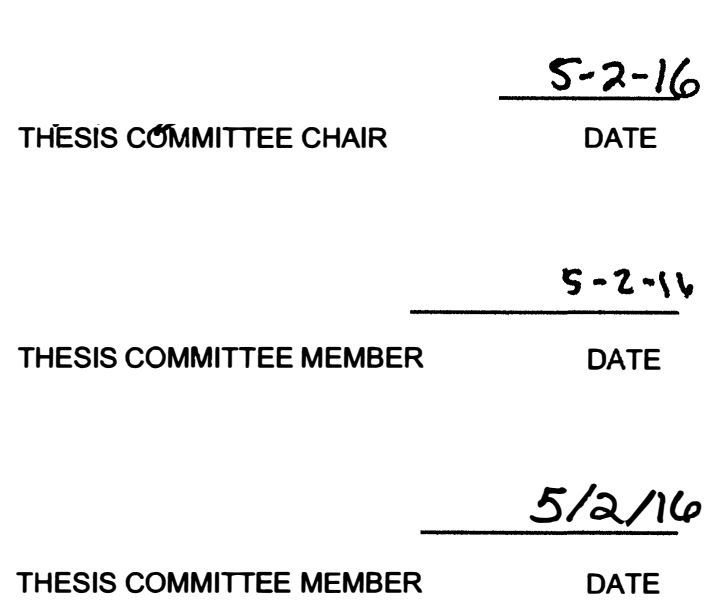

DECARTMENT/SCHOOL CHAIR OR CHAIR'S DESIGNEE 
Stress as a Moderator of Visual Perception:

Do Elevated Stress Levels Interfere with Visual Cognition?

Ashley D. Ebersole, B.A.

Thesis Submitted in Partial Fulfillment

of the Requirements for the Degree of

Master of Arts

Clinical Psychology

Eastern Illinois University

May 2016 
(C) 2016

Ashley Danielle Ebersole

All Rights Reserved 


\section{Acknowledgements}

I owe a great many thanks to a great many people for their help throughout this process of completing this thesis. Without their help my success could have never been possible.

First of all, I would like to express my sincerest gratitude to my thesis chair, Dr. Jeffrey Stowell, for his continuous support of my research and academic endeavors. I am also grateful for his kindness, insights, and encouragement to grow beyond expectations. He always allowed this paper to be my own work, but steered me in the right direction whenever I was stuck. His guidance throughout the research and writing of this thesis are immensely appreciated.

I would also like to thank the other members of my thesis committee: Dr. Fayeza Ahmed and Dr. Wesley Allan, for rigorous review and plentiful feedback. Thank you both for ensuring that this thesis is a work I can be proud of and that my tenure as an Eastern Illinois student prepared me for a lifetime of learning. Thanks also to Dr. Benjamin Guenther for sharing with me his wisdom and experience in the intricacies of cognitive psychology and an enthusiasm for science that encouraged me to persevere.

Sincere thanks to my brothers, for showing enthusiasm and pride, for laughing with me, and for keeping me sane when I needed it.

Finally, I cannot overlook my profound gratitude to my parents and to my loving boyfriend for providing me with unfailing love, support, and encouragement throughout my education and the process of researching and writing this thesis. This accomplishment would certainly not have been possible without them.

-Ashley Ebersole 


\begin{abstract}
Stress is an unavoidable aspect of human life, and despite a large body of research on stress, the relationship between chronic or traumatic stress and cognition is not yet fully explained. One component lacking research is visual attention, an area of visual cognition which is an essential part of our ability to interact with the world around us. This is especially true in the context of trauma and stress related disorders, and having a better understanding of how traumatic stress impacts attention and perception can inform psychotherapy for these issues. The current study aims to conceptualize how stressors impact the visual perception abilities of college students in a non-clinical population. Utilizing stimulus presentation software, student's sustained attention, change blindness, and inattentional blindness was measured before and after exposure to either stress inducing or neutral tasks. Participants' preexisting stress levels were measured before engaging in the tasks, and performance of participants with both high and low preexisting stress were compared. Results suggest that acute stress may not have a significant impact on visual attention performance, but that chronic stress does appear to have a detrimental effect on sustained attention and change blindness.

Keywords: Stress, Perception, Attention, Change Blindness, Inattentional Blindness, PTSD, Chronic Stress, Acute Stress
\end{abstract}




\section{Table of Contents}

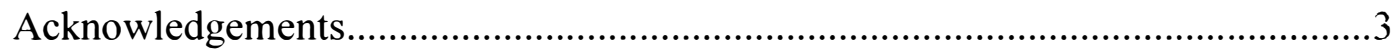

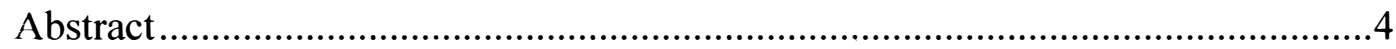

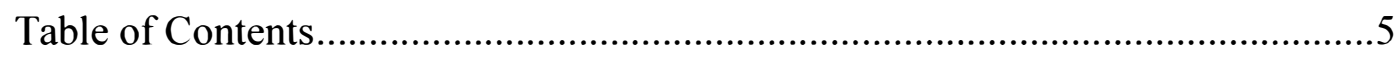

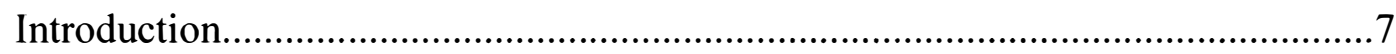

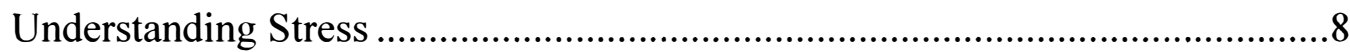

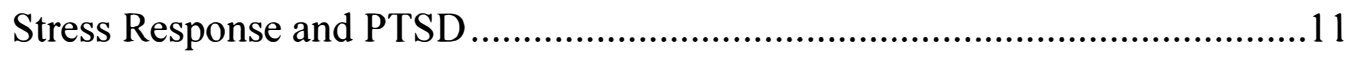

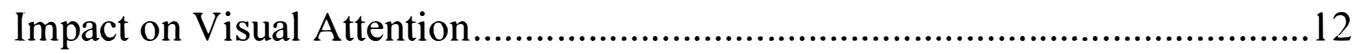

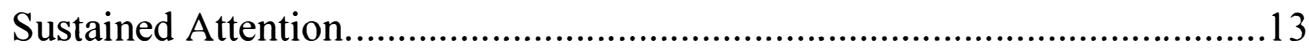

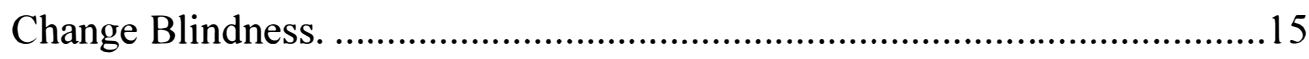

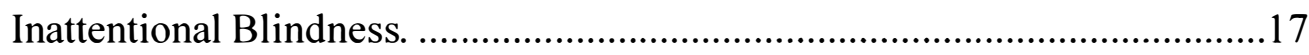

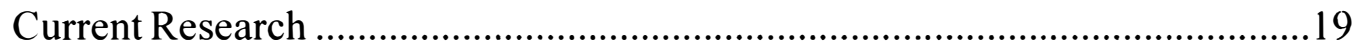

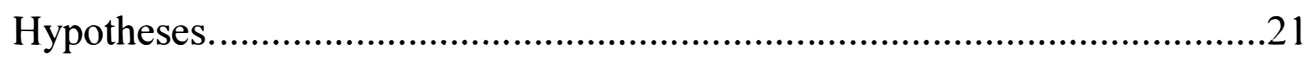

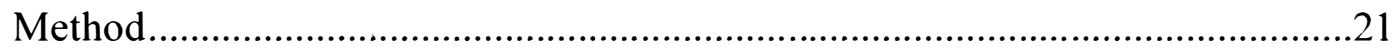

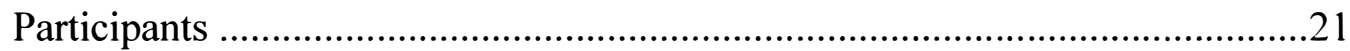

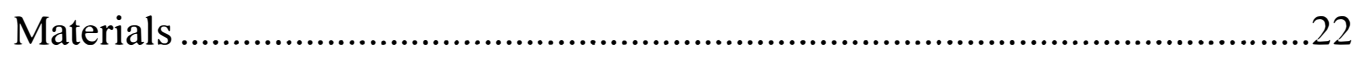

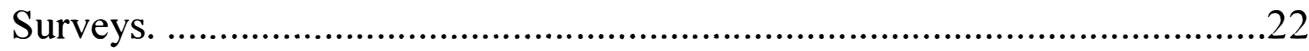

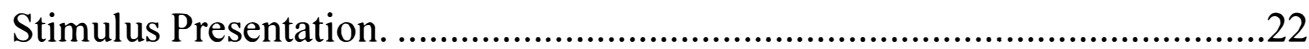

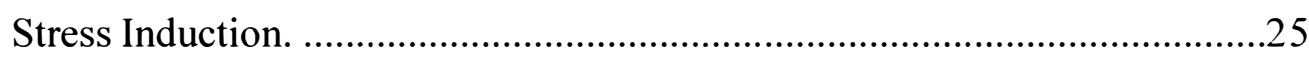

Physiological Data Recording. .............................................................26

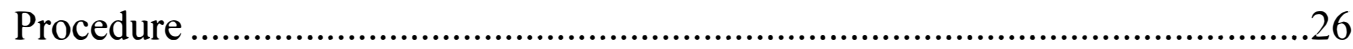

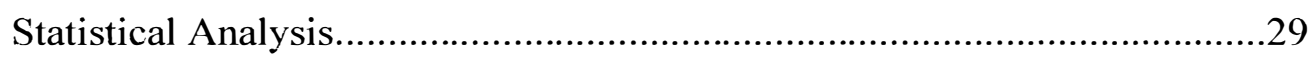

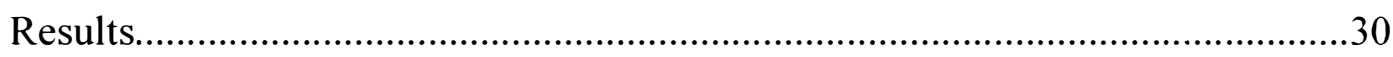

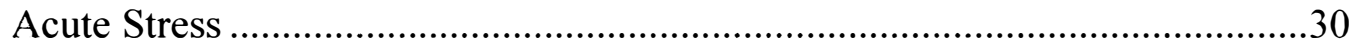

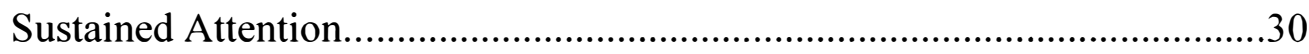

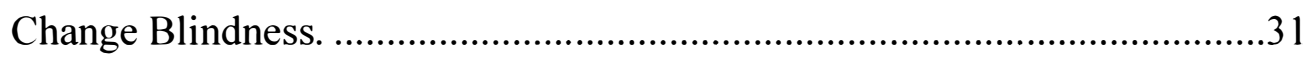

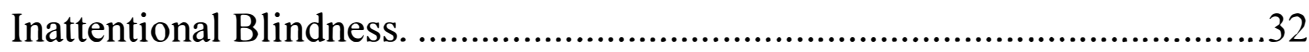

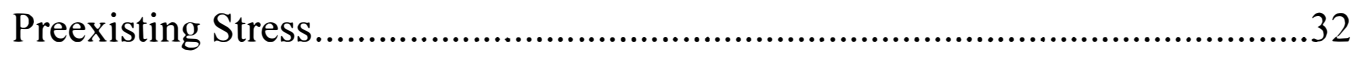

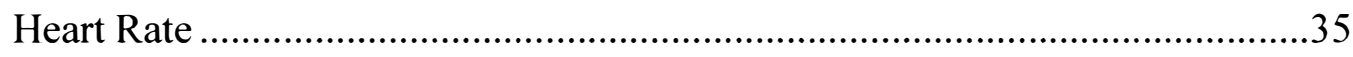

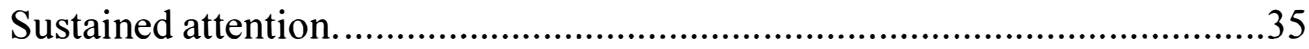

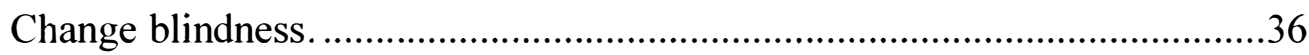




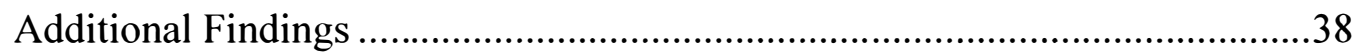

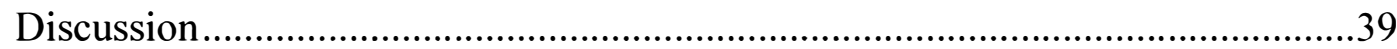

Acute Lab Induced Stress ..............................................................................

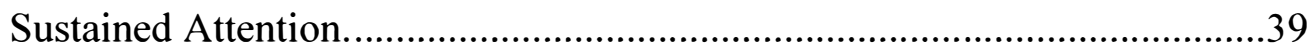

Change Blindness. ....................................................................................41

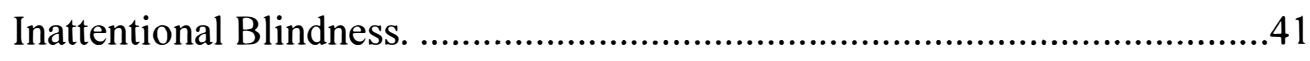

Preexisting Chronic Stress ..............................................................................42

Impact on Visual Attention..........................................................................

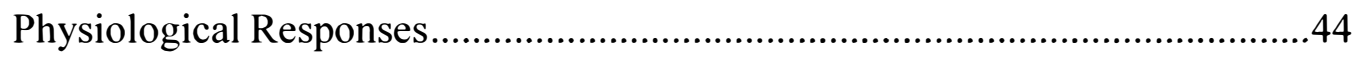

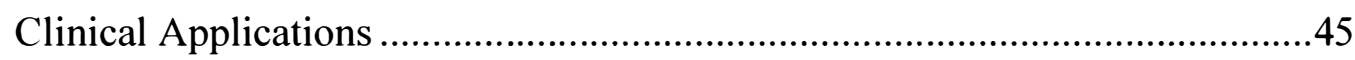

Limitations and Future Directions ...................................................................46

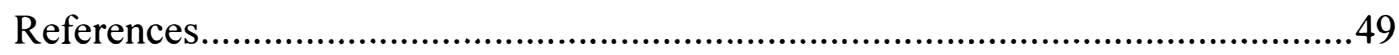

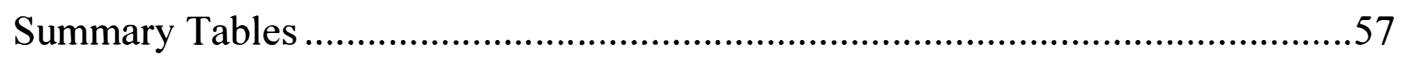

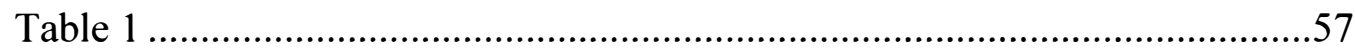

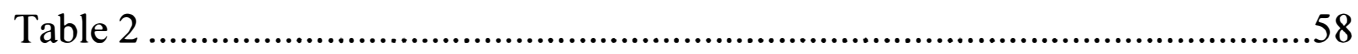

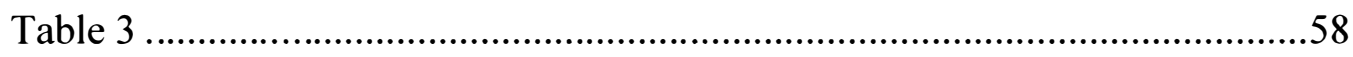

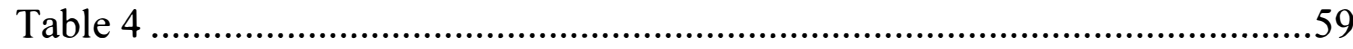

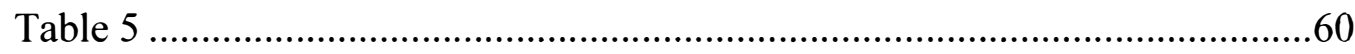

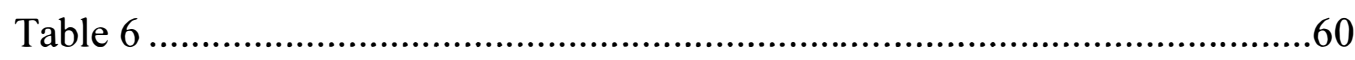

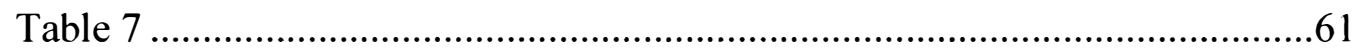

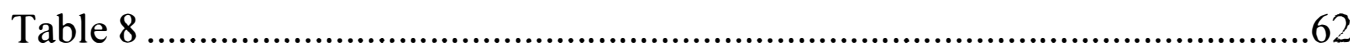

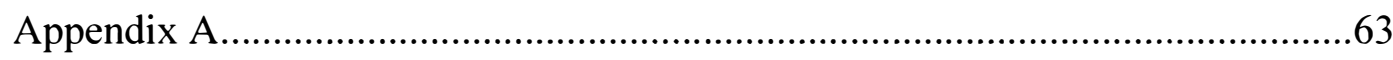

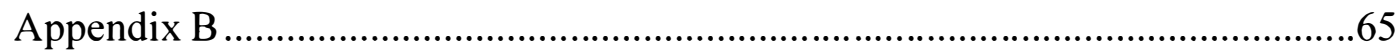

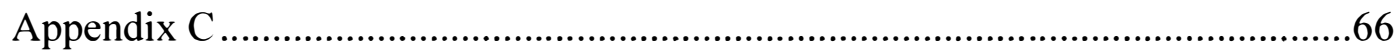

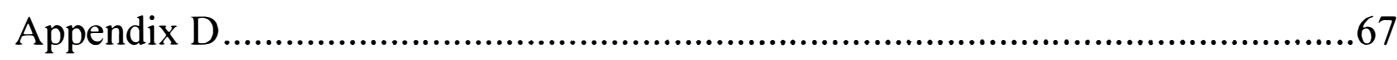

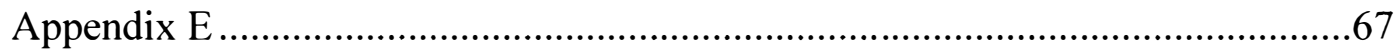




\section{Stress as a Moderator of Visual Perception: \\ Do Elevated Stress Levels Interfere with Visual Cognition?}

Stress is an unavoidable aspect of human life and, despite a large body of research on stress, the influence of excessive amounts of stress on visual cognition has yet to be fully explained. This is especially true in the context of stress and trauma related disorders; few studies have directly examined visual attention in relation to these conditions. Mental health disorders such as Depression, Anxiety, and Posttraumatic Stress Disorder (PTSD) are all closely related to elevated or chronic exposure to stress. Trauma is the result of an individual being overwhelmed and overloaded by stress or stressors, and experiencing a trauma is the number one predictor for developing PTSD. Every day thousands of men, women, and children around the world are exposed to traumatic events. In the United States alone the lifetime prevalence rate of PTSD is $8.7 \%$ (American Psychiatric Association, 2013). Understanding the relationship between traumatic stress and cognitive functioning is important when considering the use and efficacy of treatments for PTSD and other disorders connected to chronic stress. Because stress is a universal experience, and chronic or intense exposure is directly related to mental health conditions, it is crucial to gain an understanding of the ways that stress can impact us.

To better understand how traumatic stress affects visual attention, it is necessary to first understand how acute and chronic stressors can impact individual attention. One of the most important components to examine is sustained-attention, or the ability to maintain focus over time, as it plays a major role in how we gather information (Thomson, Besner, \& Smilek, 1948). Although some research has been conducted on 
this topic, further clarifying this relationship within a nonclinical population will help to establish a basic understanding of how stress can moderate attention. More specifically, there is a lack of research examining the relationship between stress and change blindness, a function of visual attention. Change blindness is the inability to detect changes occurring in the environment, and this tends to be present in most individuals to a moderate degree (Simons \& Ambinder, 2005). Similarly, little is known about how stress might influence other functions of visual attention, such as inattentional blindness. Inattentional blindness is the natural tendency to not perceive stimuli within the visual field we are attending to if we are not directly looking for it (Mack \& Rock, 1998). The current study aims to establish the effect of stressors on components of visual attention.

\section{Understanding Stress}

Stress has been characterized in a variety of ways, including Cannon's fight or flight description of stress and Hans Selye's stress model focusing on physical triggers of the stress response (Lupien, 2013). The cognitive theory of stress posits that stress is the result of an interaction between a person and the environment where demands seem harmful or unmanageable (Schlotz, Yim, Zoccola, Jansen, \& Schulz, 2011). For the purposes of this study we define stress as responses in the body that are triggered by environmental stimuli and enable a person to cope with demanding situations.

It is also important to consider that the degree to which a person responds to a specific stressor is very individualized--there are many different personality variables that appear to be correlated with elevated stress responses (Schlotz et al., 2011). These responses are a hypothesized set of traits developed through natural selection very early in our species' history, and they come with both costs and benefits (Nesse, Bhatnagar, \& 
Young, 2007). If we had adapted to be more resilient to experiencing stress, thus generating less response, it could hinder important survival mechanisms, such as our immune system. On the other hand, if we were less responsive to stressors, such as predators or other threats, it could result in death. Nesse and colleagues (2007) describe our current stress responses as adaptive despite a preference for short term benefits over long term health.

In the short term stress can be adaptive; it can activate crucial areas of the body such as neural pathways, the cardiovascular system, the immune system and more (McCabe \& Milosevic, 2015; McEwen \& Sapolsky, 1995). These responses can be beneficial when dealing with acute stressors. Much like our ancestors running from predators, having greater system-wide activation when dealing with an emergency, such as a car crash or a serious illness, can help protect our bodies from harm. For example, an increase in neural activity can help to improve memory performance and will allow a person to gather crucial information in a dangerous situation (Booth \& Sharma, 2009; McEwen \& Sapolsky, 1995). This memory could be the difference between finding shelter and dying of exposure. In modern times, this could be the memory of where to find the hospital or police station.

In contrast, extended periods of stress or chronic activation of the stress response can cause impairments. Long term or chronic exposure to stress becomes dangerous, as the effort required to keep the body in the state of alertness demanded by stress is a difficult burden, and the body can begin to suffer (McEwen, 2008). Additionally, the increased presence of stress hormones such as cortisol when unmoderated can begin to cause deterioration in the brain and the body (Lupien, McEwen, Gunnar, \& Heim, 2009; 
McEwen, 2008; Segerstrom \& Miller, 2004). This strain can lead to an increased risk for stroke and heart attack, as well as cause sleep deprivation which is related to decreases in overall physical well-being (McEwen, 2008). Furthermore, exposure to chronic stress can damage and weaken the immune system, making our bodies more vulnerable to disease (Segerstrom \& Miller, 2004). Chronic stress can cause often permanent changes within the brain, resulting in dramatic behavior changes such as increased eating, decreased sleep, or an increase in aggression or risky behavior can lead to susceptibility to other physical problems and disease (Cohen, Janicki-Deverts, \& Miller, 2007).

Most importantly, stress, both chronic and acute, seems to have a significant impact on the way that the brain gathers and process information. The hormones cortisol, epinephrine, and norepinephrine that are released during times of distress are able to cross the blood-brain barrier and interfere with key structures in the brain by binding to their respective receptors (Baker \& Kim, 2002; Lupien, 2013; McEwen, 2008). Baker and Kim (2002) show that structures such as the hippocampus, which is associated with learning and memory, have a high number of receptors that cortisol can bind to and thus are more likely to be impacted by chronic stress. In fact, evidence suggests that chronic exposure to large amounts of stress hormones can act like a poison and cause tissue decay in the hippocampus (Lupien et al., 2007). A study conducted by Liston et al. (2006) confirmed that chronic stress levels can reduce dendrite material in the hippocampus and other important brain regions by around $20 \%$. Atrophy of the hippocampus is associated with disorders such as PTSD and long term Major Depression (McEwen, 2008). These disorders both have symptoms dealing with trouble concentrating and other cognitive 
impairments, likely a direct result of cortisol's effect on the hippocampus and other brain structures.

\section{Stress Response and PTSD}

Over the past several decades a large body of research has been devoted to understanding the function and impact of stress on physical, mental, and emotional wellbeing. Due to the subjective nature of stress, there are many different explanations for stress, its purpose, and how it impacts our bodies. One of the clearest explanations of stress thus far is the immediate response of the body to stressors, called the "fight or flight" response, described by Cannon in 1929 (Milosevic \& McCabe, 2015). This response to danger triggers the release of hormones like cortisol and epinephrine, activates the crucial functions of the autonomic nervous system, and suppresses bodily functions that are not necessary for survival (McEwen, 2008). More importantly, this understanding of stress has led to many breakthroughs in the medical community in regard to serious health conditions linked to chronic stress. Doctors are better able to combat and conceptualize heart disease, gastrointestinal problems such as ulcers and irritable bowel syndrome, and even immune disorders such as HIV/AIDs (Cohen et al., 2007).

Although there is high potential for physical damage from stress, it can also induce a number of serious psychological effects. Because stress has a direct impact on crucial areas of the brain, such as the hippocampus, amygdala, and prefrontal cortex, many important systems are impacted (Weymar, Schwabe, Löw, \& Hamm, 2012). These changes can be both positive and negative, but evidence shows that stress can interfere with cognition (e.g. attention, memory, and perception) as well as increase susceptibility 
to psychological disorders (Lupien Maheu, Tu, Fiocco, \& Schramek, 2007; McEwen \& Sapolsky, 1995; Weymar et al., 2012). Disorders such as PTSD, Acute Stress Disorder, Depression, and Generalized Anxiety Disorder are all connected to unmoderated stress (Liston et al., 2006; Lupien et al., 2007). This brief list is certainly not all-inclusive; many more psychological problems are the direct result of damage caused by stress.

One of the important issues that has received more attention in recent years is the impact of high levels of stress experienced by individuals with PTSD on their cognitive functioning. Specifically, research in this area has tried to conceptualize the role of stress in major PTSD symptoms such as hypervigilance and hyperarousal, as well as related cognitive deficits that individuals with PTSD often exhibit (Barlow-Ogden \& Poynter, 2012; Dennis et al., 2004; Vasterling, Brailey, Constans, \& Sutker, 1998; Weymar et al., 2012). It is unclear if these symptoms are a direct result of elevated stress levels in the body, as there is some evidence that stress can enhance both memory encoding and attention short-term. To better understand the effects of stress on aspects of visual attention, three major components are being examined in the current study: sustained attention, change blindness, and inattentional blindness.

\section{Impact on Visual Attention}

Studies have shown that stress, from a number of different sources, can alter cognition (Allan et al., 2014; Campbell, Labelle, Bacon, Faris, \& Carlson, 2012). In the study by Allan and colleagues (2014), nurses working for telephone helplines showed significant declines in cognitive performance after stressful shifts. Despite showing an increase in processing speed during these stressful shifts, nurses were more likely to make cognitive errors (lapses in memory, attention, or concentration) and to show poorer 
work performance. It appears that glucocorticoids, the stress hormones including cortisol, inhibit the central nervous system due to the large amount of receptors located in the frontal lobe and on the hippocampus (Lupien et al., 2007; Lupien et al., 2009). Several studies have shown that after exposure to stress, memory is significantly impaired; specifically that working memory declines (Lupien et al., 2007) and that creation of false memories becomes more likely (Payne, Nadel, Allen, Thomas, \& Jacobs, 2002).

These effects seem to be even more pronounced in PTSD populations. PTSD appears to be connected to long term cognitive impairments (Vasterling et al., 2012). When tested, veterans with PTSD perform significantly worse than others on tasks of both memory and attention, and they seem to have more difficulty with being able to encode information (Vasterling et al., 1998). These veterans exhibit greater difficulty with initial learning and a significantly greater sensitivity to interference. When further exploring these trends in Vietnam veterans, Vasterling et al. (2002) found similar results; veterans with PTSD diagnoses showed poorer performance on assessments of sustained attention, working memory, and verbal information processing. Veterans deployed overseas to Iraq have also shown impairments in their sustained attention, verbal learning, and visual-spatial memory ( Vasterling et al., 2006). These additional deficits could be indicative of further damage caused by traumatic and chronic stress.

Sustained Attention. In both individuals with and without PTSD, attention is a major area of concern when examining the impacts of stress. Attention can be defined as three major actions of the mind: awareness of external and internal stimuli, processing of sensory input, and maintaining a state of alertness (Posner \& Peterson, 1989). Attention 
is a very important aspect of human cognition, as it allows individuals to perform tasks and to notice changes in the environment. This awareness is often most crucial in the visual realm; we utilize visual attention to read, to assess emotions in others, and to orient ourselves in space. Being able to sustain our attention, especially in the visual realm, is crucial to important areas of life such as work performance (Thomson et al., 1948).

Long-term sustained attention is difficult, even for the most diligent of people. Inevitably our minds will wander, shifting focus from the task at hand to more internal events such as sensations or memories (Jackson \& Balota, 2012). Smallwood and Schooler (2006) originally defined mind wandering as a shift in attention, away from a task and toward unrelated information. This mind wandering can also be described as vigilance decrement, a term used in sustained attention literature to describe the decline of performance on sustained-attention tasks as the amount of time spent on the task increases (Thomson et al., 1948). A lapse in sustained attention may seem harmless, distraction while reading is merely inconvenient, but there are plenty of instances in which it can be dangerous. Some lapses of sustained-attention can lead to serious consequences, such failing to signal when driving, not performing a thorough check in a factory, or taking more than a safe dosage of medicine.

Although it is natural for our sustained-attention to eventually deteriorate over time, typically in less than an hour, there is evidence that suggests stress can have an effect on how long we can maintain focus. Vigilance decrement typically begins to occur within 15 minutes of working on a task, but when performing a task with high demands (e.g. is mentally stressful), a decline in sustained attention can occur as soon as five minutes into the task (Warm, Parasuraman, \& Matthews, 2008). 
Previous research suggests that feeling stress changes the way that we can allocate our attention (Booth \& Sharma, 2009; Chajut \& Algom, 2003; Ellenbogen, Schwartzman, Stewart, \& Walker, 2002; Eysenck, Derakshan, Santos, \& Calvo, 2007; Weymar et al., 2012). Stressors appear to have a detrimental effect on attention control, focus is naturally drawn away from a task and toward the source of stress whether it is internal (e.g. thoughts, discomfort) or external (e.g. environment, social evaluation) (Eysenck et al., 2007). Research conducted by Ellenbogen et al. (2002) showed similar results, and suggested that elevated levels of cortisol impede selective attention, which in turn interferes with the ability to filter out irrelevant information. This effect was replicated in the study by Booth and Sharma (2009). This finding is also supported by Mogg et al. (1990) in which this interference appears to make individuals more likely to shift attention toward stimuli that are threatening, such as words with negative connotations. Exposure to acute stress has been shown to increase the encoding of aversive stimuli, and seems to be a connected to the strong reactions of individuals with PTSD (Weymar et al., 2012). Together this evidence shows that both chronic and acute stress exposure can impair the mind's ability to direct and control attention.

Change Blindness. Even when attention is focused, and a person is closely attending to a task, there are still times when stimuli are missed. Change blindness is the failure to notice large changes in the environment, and it can occur even when we are paying attention (Simons \& Levin, 1997). Even when we are actively searching for changes, we tend to struggle with locating them (Simons \& Ambinder, 2005), although they appear glaringly obvious once we notice them. 
Simons and Levin (1997) have performed a number of classic experiments that showed the extent to which we fail to notice changes in our surroundings. One example is the door event, where an experimenter begins to give directions to a participant, but they are interrupted when two people carry a door or other large item between the experimenter and the participant. While the door is passing by, the experimenter switches places with another experimenter who is dressed and looks completely different. In this experiment only $50 \%$ of participants noticed that the person changed (Simons \& Levin, 1997), showing how dramatically we can overlook changes after a momentary interruption. In later studies it has been shown that even in the absence of some form of disruption, we are still likely to fall prey to change blindness (Simons, Franconeri, \& Reimer, 2000). This appears to be true even for very large changes if they occur gradually. Change blindness seems to occur any time there is a diversion which interrupts the change signal (Simons \& Ambinder, 2005) similar to the way that stress can impact sustained-attention. There is little to no research regarding how stressors affect levels of change blindness.

Understanding how stress could further increase change blindness or improve accuracy in change detection could prove very beneficial in many ways. Change blindness can prove dangerous in numerous high-risk situations. One such example of a high-risk situation is eyewitness reports. In an experiment conducted by Fitzgerald, Oriet, and Price (2014), participants were instructed to closely attend to a videotaped crime in which there was a change between an innocent person and a criminal. They then asked participants to identify the criminal in a lineup following a short filler activity. Only about one third of the participants noticed the change; of those that did not identify 
the change (were change blind) only about $28 \%$ showed accuracy in their line-up (Fitzgerald et al., 2014). Individuals experiencing change blindness were more likely to identify the innocent person and filler individuals as culprits, suggesting that eye-witness accounts are highly unreliable given that change blindness can occur even when we feel that we are paying attention.

Additionally, it is important to note that other research has shown that individuals who understand change blindness will still experience it (Levin, Momen, Drivdahl, \& Simons, 2000). In fact, both those who are and are not aware of change blindness tend to overestimate their ability and the ability of others to detect change. Research has shown that change blindness occurs across multiple cultures, although it can vary in presentation such as being more aware of focal versus contextual changes (Masuda \& Nisbett, 2006). Because this is a widespread and relevant phenomenon, understanding the way in which it can fluctuate in relation to our mental health is very important.

Inattentional Blindness. Similar to change blindness is the natural phenomena of inattentional blindness. Originally described by Mack and Rock (1998), inattentional blindness is the inability to perceive stimuli when they are not being directly attended to. It is also referred to sometimes as "looking without seeing" or "sighted blindness." Although change blindness describes the phenomena where we are unable to detect changes to objects or our environment, inattentional blindness is being unable to even perceive objects at all if attention is not given to them (Simons \& Chabris, 1999). In the original inattentional blindness study, where participants engaged in a decoy activity and an unexpected stimulus was presented within their area of focus, close to $25 \%$ of participants failed to observe the stimulus (Mack \& Rock, 1998). When they altered the 
location of the stimulus to be presented away from the target object and with the fixation cross, this percentage increased to close to 75 percent. These results suggest that we direct our focus to tasks which we have prioritized and new or additional information is much more difficult to encode.

Inattentional blindness, as a natural function of the human mind, serves as a way to allow us to direct our attention. Without an ability to filter out visual information that we perceive we would be unable to comprehend our experience. To many, both change blindness and inattentional blindness are alarming when observed; we are of ten lead astray by our belief that our minds are capable of viewing and encoding a vast amount of rich visual information at all times (Levin, Drivdahl, Momen, \& Beck, 2002). This effect can be seen in occurrences where we become aware of our own inattentional blindness, such as when we fail to see a friend in a crowd while we are searching for an address or specific building. In the study conducted by Simons and Chabris (1999) where participants observed a scene with people passing a basketball and the unexpected stimulus was a gorilla walking by, participants were often alarmed by their failure to observe such an unusual stimulus (Simons, 2000). We often have the erroneous belief that unusual events will capture our attention (Levin et al., 2000), however unusual stimuli appear to be just as likely to go unnoticed.

Even more alarming, are the instances of inattentional blindness that result in danger, such as a driver failing to see someone step out into the crosswalk or a car in their blind spot, or a nurse missing an allergy on a patient chart. Although inattentional blindness is beneficial by helping us limit the amount of information we attempt to process, it can also result in danger. For this reason it is important to gain an 
understanding of how stress might impact this phenomenon. If stress were to cause an increase in inattentional blindness a situation perceived as dangerous could become even more so and in turn increase the body's stress response. Additionally, it is important to understand how changes in visual perception abilities might impact mental health symptoms such as hypervigilance.

\section{Current Research}

There is a startling lack of information regarding the interaction of stress with levels of visual attention. The phenomena of change blindness can have a significant impact on our ability to function in social situations and in important areas of work performance. As mentioned previously, inattentional blindness is crucial in many highrisk activities such as driving. Research into these areas could help to clarify the dangerous effect that stress can have on our performance in everyday activities and how allowing ourselves to become overwhelmed by stress can endanger us more ways than just feelings of irritability and exhaustion. Additionally, clarifying this relationship in a nonclinical population could set up a foundation for exploring this relationship in stressrelated disorders such as PTSD or Anxiety in the future. Already an underserved population, victims of trauma could potentially be at additional risk for car-accidents and lapses in attention than other populations, especially in situations that trigger hyperarousal and stress hormone activation. The aim of this study is to examine the cardiovascular and behavioral changes associated with acute mental stress. Specifically, this study will examine behavioral measures of sustained-attention, change blindness, and inattentional blindness. 
To produce stress, this study utilized the mental arithmetic task from the Trier Social Stress Test (TSST), also called the serial subtraction task (Kirschbaum, Pirke, \& Hellhammer, 1993). These lab-induced stressors are categorized as acute time-limited stressors (Segerstrom \& Miller, 2004) due to the fact that they are stressors which are only produced in the lab and are not the same as those occurring in natural settings. This type of stressor is ideal for examining the immediate effects of moderate stress levels on the participant's ability to perceive and attend to the environment. This task has been shown to reliably evoke cortisol responses indicating increased stress levels (Lupien, 2013). The amount of stress induced through this method is comparable to what would be experienced in a natural setting, making it an ideal way to ethically create stress in participants.

An important consideration of this study, however, is that sustained attention and change blindness tasks are inherently stress inducing (Hancock \& Warm, 1989; Warm et al., 2008), as are most tasks that require mental effort. Therefore, within this study physiological indications of stress levels will be measured throughout the process. Participants reported their current stress levels upon arrival and their average stress over the past month was assessed. Having this self-report of stress levels, combined with the physiological fluctuation in stress before, during, and after the stress inducing task provided an overall picture of each participant's level of stress response. Taken in combination with the data showing performance on the visual attention tasks, a clear picture of how stress can interfere with visual performance should appear. Based on the research examined previously, individuals with greater pre-existing stress levels will likely show poorer performance on the tasks, and therefore it is expected that these 
individuals will show a greater physical stress response to all tasks. Similarly, there should be a change in performance between the initial task performance and the performance following the stress task.

Hypotheses. In an effort to further the understanding of the relationship between stress and visual attention, the current study aims to test the following hypotheses.

1. Performance on sustained attention tasks will be significantly poorer after exposure to a stressful situation. Based on evidence found in vigilance decrement research, it is expected in this study that sustained attention will naturally decline over time both within individual blocks of the task and across the attention task as a whole. Additionally, because it is likely more difficult to maintain focus, this effect should be pronounced after experiencing acute stress.

2. Performance on change blindness tasks will be significantly poorer after exposure to a stressful situation.

3. Participants exposed to stress will exhibit poorer performance on the inattentional blindness task than their peers.

4. Participants who self-report a higher level of preexisting stress will show an overall impairment in performance on all measures of visual attention.

\section{Method}

\section{Participants}

Undergraduate students at Eastern Illinois University enrolled in the Introductory Psychology Research Participation Pool were recruited to participate in the current study in exchange for research participation credit. The study was advertised in the SONA 
online registration system, with a basic description of the study, and interested students signed up voluntarily for individual time slots.

A total of 54 students volunteered, and all were randomly assigned to either the stress or non-stress conditions, 27 in each group. As shown in Table 1, the majority of participants were under the age of 20. Participants were a majority female (72.2\%) Caucasian (61.1\%) freshman (68.5\%).

\section{Materials}

\section{Surveys.}

Demographic survey. The demographic survey consisted of four demographic items (age, gender, school year, and ethnicity), and one item for assessing current stress level. This item asked "How would you rate your current level of stress?" on a Likert scale where $1=$ Not at all Stressed and $7=$ Overwhelmed, Appendix A.

Perceived stress. The Perceived Stress Scale (PSS) (Cohen, 1994) measures feelings of stress occurring over the past month, where frequency was rated on a Likert scale $(0=$ never, $4=$ very often $)$ utilizing questions such as "In the past month, how often have you felt that you were unable to control the important things in your life?" (See Appendix A). In college student samples, the PSS has shown a coefficient reliability alpha of 85 (Cohen, Kamarck, \& Mermelstein, 1983). The PSS has been proven to be an effective measure of general stress levels, and the 10 -item version appears to be the most reliable compared to the 4- and 14-item variants (Lee, 2012).

Stimulus Presentation. Visual stimuli for this experiment were created with the program OpenSesame (Mathôt, Schreij, \& Theeuwes, 2012), which is an open source python programming tool that allows users to create and run custom experiments. A total 
of three tasks were created in OpenSesame: a Sustained Attention task, a Change Blindness task, and an Inattentional Blindness task.

Sustained Attention. The Sustained Attention task, modeled after the Sustained Attention to Response Task developed by Robertson et al. (as cited in Jackson \& Balota, 2012), involves participants viewing a series of five digits (e.g. "1 2345 ") on the screen and responding to indicate whether a specific number (e.g., "4") is or is not present in the series (appendix B). Although the SART task is typically a go no-go task, the variation utilized for this experiment was a continual performance task that required participants to respond both to the presence and absence of the critical number. These digits were displayed in a white font presented on a black screen, and each series appeared on the screen for a total of $500 \mathrm{~ms}$ before moving on to the next series. This task had a series of 20 practice trials, followed by three sets of 50 experimental trials. Between each of the experimental sets, participants were given the opportunity to take a short break. The task took an average of six minutes to complete. Accuracy for the sustained attention tasks was defined as the percentage of hits versus misses, where no response or a timeout was counted as a miss.

Change blindness. Based on the flicker paradigm created by Rensink, O'Regan, and Clark (1996), the Change Blindness task utilized pairs of images separated by a gray mask to measure change blindness. The pairs of images were identical aside from one altered aspect of the image, such as an item being removed, added, or shifted in any direction. For example, a scene of a barn next to a body of water was altered by extending the reflection of the barn in the water. The differences between the images are readily apparent when there is no mask being used. Each image in the pair was presented 
in an alternating order for $250 \mathrm{~ms}$, separated by a blank gray mask for $80 \mathrm{~ms}$ between each presentation (see Appendix C). Participants were shown each pair of images repeatedly until they correctly identified the change by clicking on the region of interest with their mouse, or until 30 seconds had elapsed. The task began with a practice image pair to introduce participants to the procedure and was followed by 10 pairs of experimental images. For the post-test, a second version of the task was created with an additional 10 pairs of images and a new practice item so that prior learning would not interfere with the results. The change blindness task took an average of three and a half minutes for a participant to complete. Accuracy for these tasks was measured as a percentage of the number of correct clicks (always 1) over the total number of misses for each image. For images where no response was given in the allotted time, accuracy was considered to be zero.

Inattentional blindness. Inattentional Blindness was measured utilizing a task designed to duplicate the paradigm developed by Mack and Rock (1998). The inattentional blindness task utilized misdirection by having participants focus on an activity that was not the primary purpose of the experiment. Participants were instructed to focus on a small fixation cross for $1500 \mathrm{~ms}$, until a larger cross appeared for $200 \mathrm{~ms}$ before being replaced with a mask image that lasted for $500 \mathrm{~ms}$ (see Appendix D). The crosses were white font on a black background, and were located within a circled area of the window. Participants made a judgement of which arm (horizontal or vertical) of the larger cross was longer or if both arms were the same length. Participants had an indefinite amount of time to respond to this multiple choice question. This was true for all 
eight trials in the experimental portion of the task and for the single practice trial presented at the beginning of the task.

In the experiment, participants were presented with seven non-critical trials and only one critical trial. In the critical trial, an additional stimulus (a white square located in the upper left hand quadrant) was presented within the immediate visual field near the second cross. After providing their answer to the arm length question on the critical trial, participants were also asked if they observed anything additional in the last trial other than the crosses or the mask. If they responded in the affirmative they were asked to describe the additional object seen to assure their understanding. Inaccurate descriptions of the white box were considered as missing the critical stimulus. The critical trial comes after the participants have responded to three non-critical trials, and was followed by an additional three non-critical trials. All three attentional tasks were presented in $1024 \mathrm{px}$ by $768 \mathrm{px}$ window on a standard desktop computer with an 18 -inch monitor with participants seated approximately 20 inches away.

Stress Induction. Stress was produced utilizing a mental arithmetic task modeled after the Trier Social Stress Test (TSST), also called the serial subtraction task (Kirschbaum et al., 1993). Participants were instructed to subtract increments of 13 from 1,022 out loud while being monitored by the experimenter. They were instructed to work as quickly as possible, while making as few mistakes as they could. Each time a participant made a calculation error, the experimenter informed the participant that they were incorrect and repeated the original large total to cue the student to start over. Participants were provided with very little feedback from the experimenter, limited to instances of incorrect answers. The experimenter recorded correct responses and the 
number of restarts required on a recording form hidden from the participants' view on a clipboard (see Appendix E). A cellphone timer was utilized as a stopwatch by the experimenter. Participants assigned to the non-stress condition stayed in the sound proof booth for their neutral task. These students observed a ten minute video of nature scenes with gentle music from the BBC program Planet Earth.

Physiological Data Recording. To record cardiovascular changes experienced throughout the experiment, all participants wore a Zephyr BioHarness 3 professional Bluetooth heart rate monitor, which is a small unit mounted to a chest strap that wirelessly gathered heart rate data. This data was recorded and monitored in real-time using the accompanying software suite, Zephyr OmniSense (Zephyr, 2013).

\section{Procedure}

Informed consent was obtained from all participants before beginning the experiment, and all data was gathered following guidelines established by the American Psychological Association and with approval from the IRB. All students willing to participate in the study were informed that they were free to withdraw at any time. All data were collected in a soundproof booth. The purpose of this setting was to minimize external distractions native to the university environment that could confound an individual's level of attention for a task. Responses were kept completely anonymous and all data were used in aggregate. Participation in the study took a maximum of 60 minutes, typically closer to 45 minutes.

After being recruited through the SONA website, participants arrived to the lab at a specified appointment time. Before beginning participation, participants were informally assessed for epilepsy or light sensitivity, heart conditions, and claustrophobia 
to ensure safe participation. Following completion of the informed consent form, students were instructed to put on the heart rate monitor ensuring proper positioning. After a reliable signal was verified, recording of the heart rate data was started. Participants were then asked to sit without activity for a short period of five to seven minutes, allowing them to acclimate to the lab setting and to establish a baseline resting heart rate (RHR). This also allowed for the chance to ensure that the heart rate monitor was being worn correctly, and that the signal from the monitor to the computer was reading properly. Following the establishment of the RHR, students completed the initial survey. For this PSS and demographic survey, completion of the materials occurred on a Google Forms online survey, accessed on a lab computer.

Experimental manipulation allowed for participants to be randomly assigned into one of two conditions, stressed and non-stressed, while counterbalancing for the order of task presentation minimized the effects of task order and learning. Independent variables in this experiment included a between-subjects stress condition (stress or non-stress condition) and a within-subjects factor of time (pre- and posttest).

The tasks completed next varied based on group assignment and counterbalancing. Students first completed either the Sustained Attention task, or one of the two versions of the Change Blindness task. Following the completion of the first task, participants immediately began completing the second task. At the beginning of every task, the researcher recorded the time and the participant's current heart rate. No feedback about performance was provided to the students for any of the tasks. Data was recorded through OpenSesame and later converted into an SPSS data file for analysis. 
For the sustained attention task, students first viewed simple instructions explaining the task. They then were given additional instructions for a short practice section which contained 20 series of numbers. A second set of instructions followed the practice session, alerting participants to the beginning of the experimental phase of the task. Students continued with the continual response procedure for the next three sets of 50 series. Between each set was an option for the participants to take a short break; they were allowed as much time as they desired for the break.

Similar to the sustained attention task, participants began the change blindness task by first viewing an overview of the task instructions. A set of practice instructions were given, and students completed a practice trial of the task which contained only one image pair. This was followed by another set of instructions which alerted participants to the beginning of the experiment. In the experimental phase, students viewed ten pairs of images. Participants each completed one practice item and ten trial items before moving on to the next task in the experiment.

After completion of the first two visual computer tasks, participants then engaged in either the stress inducing task (TSSS) or the neutral task (nature video) depending on their random assignment to the conditions. Both of these tasks lasted a total of ten minutes.

Following completion of the stress inducing or neutral tasks, participants returned to completing stimulus presentation tasks on the computer. They completed three additional tasks, with order varied, two of which were repeats of the sustained attention task and the change blindness task. The sustained attention task followed the same random number selection procedure for the second completion. The second change 
blindness task contained ten new pairs of images in order to combat the effect of learning on performance. The third task measured inattentional blindness. Following the completion of all stimulus presentation tasks, clients were instructed to remove the heart rate monitor and exit the sound proof booth. Students were given the opportunity to ask questions and a verbal debriefing occurred. Data gathered in the Google forms, the heart rate monitor, and each stimulus presentation program were gathered into SPSS for analysis.

Statistical Analysis. A mixed factorial ANOVA was conducted on the performance (both accuracy and response time) of participants on each task to determine if there is a significant difference between the non-stressed and the stressed conditions over time. A similar set of analyses was repeated on the response times of participants on all tasks. To determine if preexisting stress level predicted an overall impairment in performance on either sustained attention or change blindness tasks, a median split was performed on the participant scores of participants on the PSS. Participants were evenly sorted into high and low pre-existing stress levels. Mixed factorial design ANOVAs were conducted again with the PSS median scores added as an additional betweensubjects variable to see if these scores impacted performance. A Chi-square test was run on the inattentional blindness results and the stress conditions. Pearson's $r$ correlations were calculated to examine relationships between variables. Lastly, ANOVAs for mixed factorial designs were conducted on the changes in HR across three different time points for both the sustained attention and the change blindness tasks. These included average HR at the pretest, the intervention, and the posttest. A median split was performed on the PSS scores to gain additional clarification and exploration of the results after initial 
results yielded very near significant trends. The original analyses were repeated with PSS median scores as an additional factor. All analyses had alpha levels set at .05.

\section{Results}

\section{Acute Stress}

Sustained Attention. The first analyses examined the impact of acute stress on performance on sustained attention tasks (see Table 2). Results indicated that there was no significant interaction between stress condition and time (pre/post) on accuracy scores. There was also no significant interaction between stress condition and blocks over time. However, there was a significant main effect of time, $F(1,51)=22.86, p<.001, \eta_{p}{ }^{2}=$ .31 , where overall performance on the posttest $(M=.35, S D=.20)$ was significantly better than performance on the pretest $(M=.25, S D=.15)$. There was also a significant main effect of separate blocks over time, $F(2,102)=6.53, p=.002, \eta_{p}{ }^{2}=.11$, where participants' performance improved from one block to the next. Multiple t-tests with Bonferroni corrections further indicate that the pairwise comparisons between blocks one and three were statistically significant $(p=.003)$, however no other pairwise comparisons achieved significance. Average performance on both trials showed that accuracy on the third block of the task $(M=.33, S D=.03)$ was significantly better than on the first block $(M=.28, S D=.02)$. Overall performance improved over time; the third posttest block $(M=.37, S D=.22)$ was better than the second $(M=.35, S D=.22)$, and the first $(M=$ $.33, S D=.21)$, which was also better than the third $(M=.28, S D=.18)$, second $(M=.26$, $S D=.17)$, and first $(M=.22, S D=.16)$, pretest blocks. These results did not support the hypothesis that sustained attention performance would be impaired by acute stress, or that a decline in performance would happen over time due to vigilance decrement. 
To further examine the potential effect of stress on sustained attention abilities, an additional analysis of variance for mixed factorial designs was conducted on the average response times on the sustained attention tasks. Results indicate that there were no significant interactions between stress condition and time or between stress condition and blocks over time. There were also no significant main effects. These findings did not support the hypothesis that acute stress would impair sustained attention performance.

Change Blindness. To test the prediction that participants experiencing acute stress would exhibit poorer performance on change blindness tasks, a two-way analysis of variance for mixed factorial designs was performed on the accuracy scores (see Table 3). Results showed that there was no significant interaction between stress condition and time. However, there was a significant main effect of time, $F(1,52)=4.59, p=.04, \eta_{p}{ }^{2}$ $=.08$. Participants in both conditions showed significantly higher accuracy in their posttest performance $(M=.79, S D=.15)$ than they did in their pretest performance $(M=$ $.74, S D=.15$ ). A two-way analysis of variance for mixed factorial designs performed on the average response times for the change blindness tasks found no significant interaction between stress condition and time, nor any significant main effects. Together, these results did not support the hypothesis that acute mental stress would impair performance on change blindness tasks.

To further examine the potential effect of stress on change blindness, an additional analysis of variance for mixed factorial designs was conducted on the average response times. Similar to the sustained attention tasks, results indicate that there were no significant interactions between stress condition and time, nor was there a significant 
main effect. These findings did not support the hypothesis that acute stress would impair performance on change blindness tasks.

Inattentional Blindness. A chi-square test for independence was conducted on the percentages of participants in the stress and non-stress conditions who detected the critical stimulus in the inattention blindness task. Contrary to the hypothesis that stress would lead to poor performance on the inattentional blindness task, results indicated that stress condition and detection rates were not significantly related, $\chi^{2}(1, N=54)=2.85, p$ $=.09$, Cramer's $V=.230$.

\section{Preexisting Stress}

To examine whether preexisting stress had an effect on overall visual attention abilities, the original analyses were repeated, but the PSS median score was included as an additional between-subjects variable. First, sustained attention performance was analyzed using an ANOVA for mixed factorial designs (see Table 4). Results indicate that there was a significant interaction between median PSS scores and time on participants' accuracy, $F(1,49)=5.68, p=.02, \eta_{p}{ }^{2}=.10$. Participants in the acute stress and the control conditions who reported lower preexisting stress showed significantly greater improvement from pretest $(M=.24, S D=.14)$ to posttest $(M=.39, S D=.20)$ than did their peers. Participants with high PSS scores had greater accuracy during pretest $(M$ $=.26, S D=.17)$, but showed significantly less improvement $(M=.31, S D=.20)$, see Figure 1. Thus, the significant interaction partially supported the fourth hypothesis that preexisting stress had a negative impact on participants' overall visual attention abilities, at least for accuracy on sustained attention. However, when running this analysis on the response times for the sustained attention tasks, no significant results were found. 
0.40

0.35

0.30

0.25

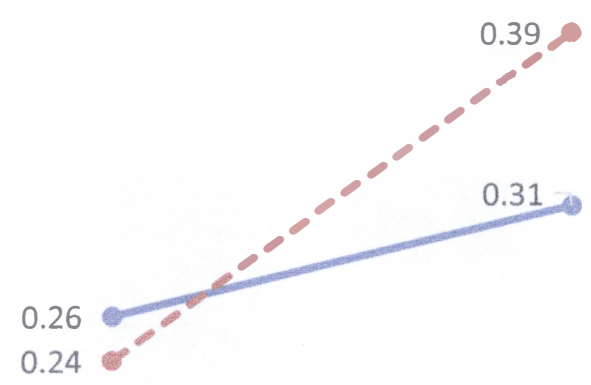

High PSS

$-\infty$ - Low PSS

0.20

0.15

$\begin{array}{ll}\text { Pretest Posttest } & \end{array}$

Figure 1. Accuracy on the sustained attention task over time by PSS level.

To further explore the impact of preexisting stress on visual attention, the relationship of the PSS median scores with change blindness performance was examined (see Table 5). An ANOVA for mixed factorial designs was conducted and results showed that the interaction between PSS median scores and time only approached significance, $F(1,50)=3.59, p=.06, \eta_{p}{ }^{2}=.07$. The ANOVA conducted on change blindness response times and PSS scores also did not yield any significant results. These results did not support the fourth hypothesis that chronic stress impairs overall visual attention abilities. When running these analyses on response times for the change blindness tasks, no significant results were found. However, a trend appeared within the response times where the majority of participants exhibited faster response times, but participants in the stress condition with higher preexisting stress exhibited a slower reaction time (figure 2 and 3 ). 
12200

12000

11800

11600

11400

11200

11000

10800

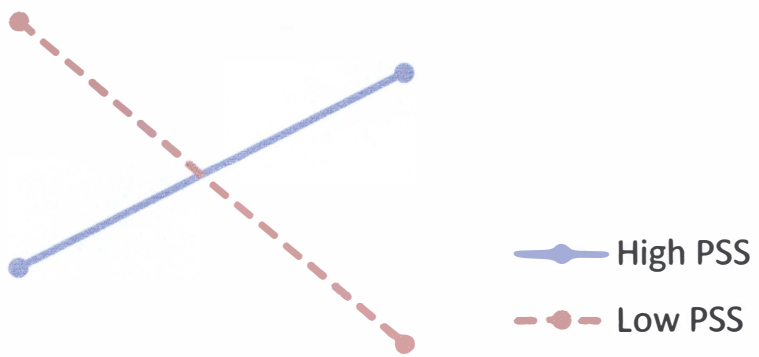

10600

10400

10200

10000

Pretest Posttest

Figure 2. Reaction time changes for the change blindness task in the stress condition by PSS score

12500

12000

11500

11000

10500

10000

9500

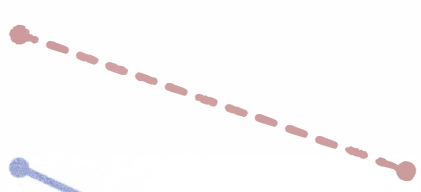

9000

8500

\section{Pretest Posttest}

Figure 3. Reaction time changes for the change blindness task in the control condition by PSS score

To examine how preexisting stress might influence inattentional blindness, a chisquare test was run on the percentages of participants who had high and low PSS median scores who either reported seeing or not seeing the critical stimuli. Results show that PSS scores and detection rates were not significantly related, further failing to support the hypothesis that higher preexisting stress levels would impair participants' overall visual attention abilities. 


\section{Heart Rate}

Sustained attention. The heart rate data gathered throughout participation was examined to understand how physiological signs of stress fluctuated. A multi-way ANOVA for mixed factorial designs was conducted on the heart rate (HR) change over time for the sustained attention tasks (see Table 6). Results indicated that there were no significant interactions between stress condition and heart rate changes on the sustained attention tasks, and there were also no significant main effects of the HR changes. However, there was a significant quadratic trend in the interaction between the HR changes and the stress condition, $F(1,49)=5.42, p=.02, \eta_{p}{ }^{2}=.10$. Participants in the stress condition showed a higher heart rate during the intervention $(M=86.55, S D=$ $11.80)$, than during both pretest $(M=82.74, S D=9.60)$ and the posttest $(M=81.79, S D=$ 11.97). In comparison, those in the non-stress condition showed a slight reduction during the intervention $(M=88.67, S D=24.89)$ relative to their pretest $(M=90.31, S D=31.87)$ and posttest HR $(M=91.30, S D=31.95)$, see Figure 4. This result matches the expectation that acute stress would manifest as physiological arousal. However, preexisting stress, as measured by PSS scores did not appear to have a significant impact on how participants in the study reacted to the acute laboratory stress. 


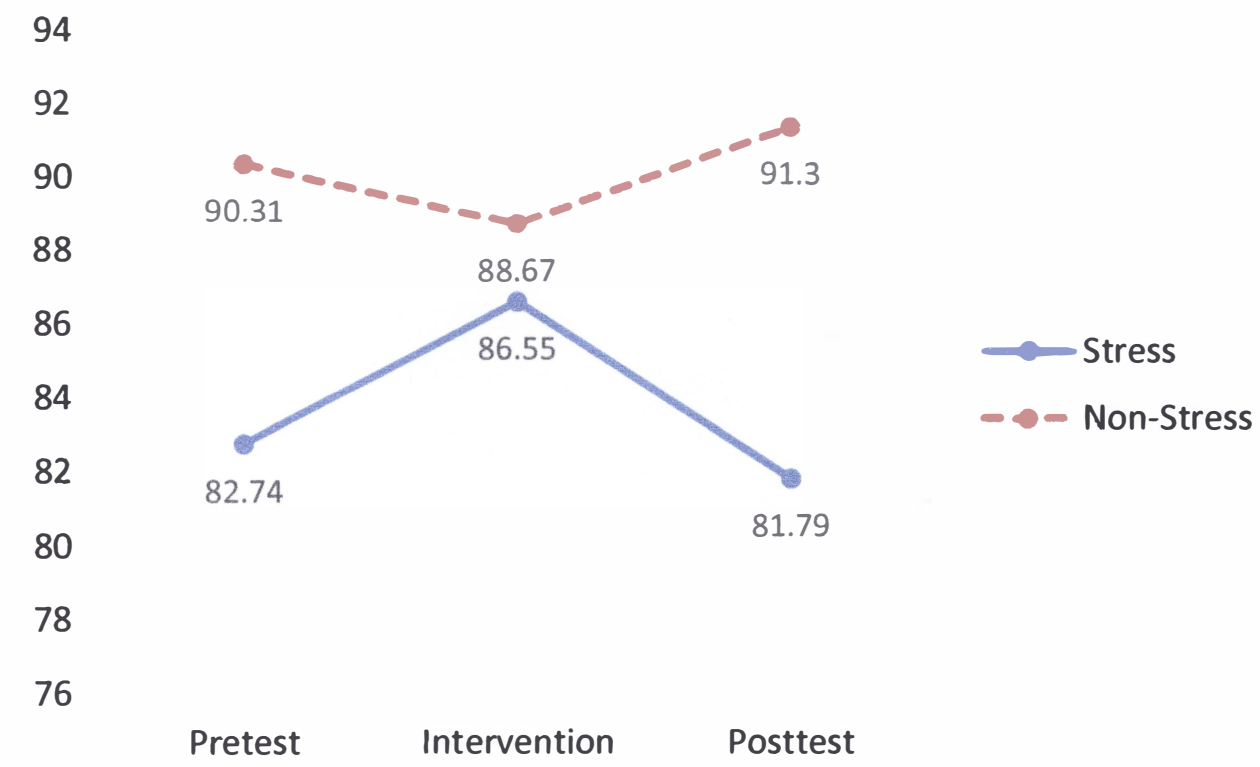

Figure 4. Heart rate change across sustained attention tasks by condition.

Change blindness. A multi-way ANOVA for mixed factorial designs was conducted on the HR change over time for the change blindness tasks (see Table 7). A significant quadratic trend was observed for the main effect of HR change across the change blindness tasks, $F(1,51)=5.59, p=.02, \eta_{p}{ }^{2}=.10$. All participants showed an increase in HR during the intervention task $(M=87.59, S D=19.20)$ compared to the average HRs during the pretest $(M=84.06, S D=23.98)$ and posttest $(M=82.39, S D=$ 23.96). This trend is close to the expectation. However, the participants in the non-stress condition also showed an increase during the intervention $(M=87.70,88.67$, and 86.33), though it was not as large as participants in the stress condition $(M=80.55,86.55$, and 78.61). (See figure 5). 


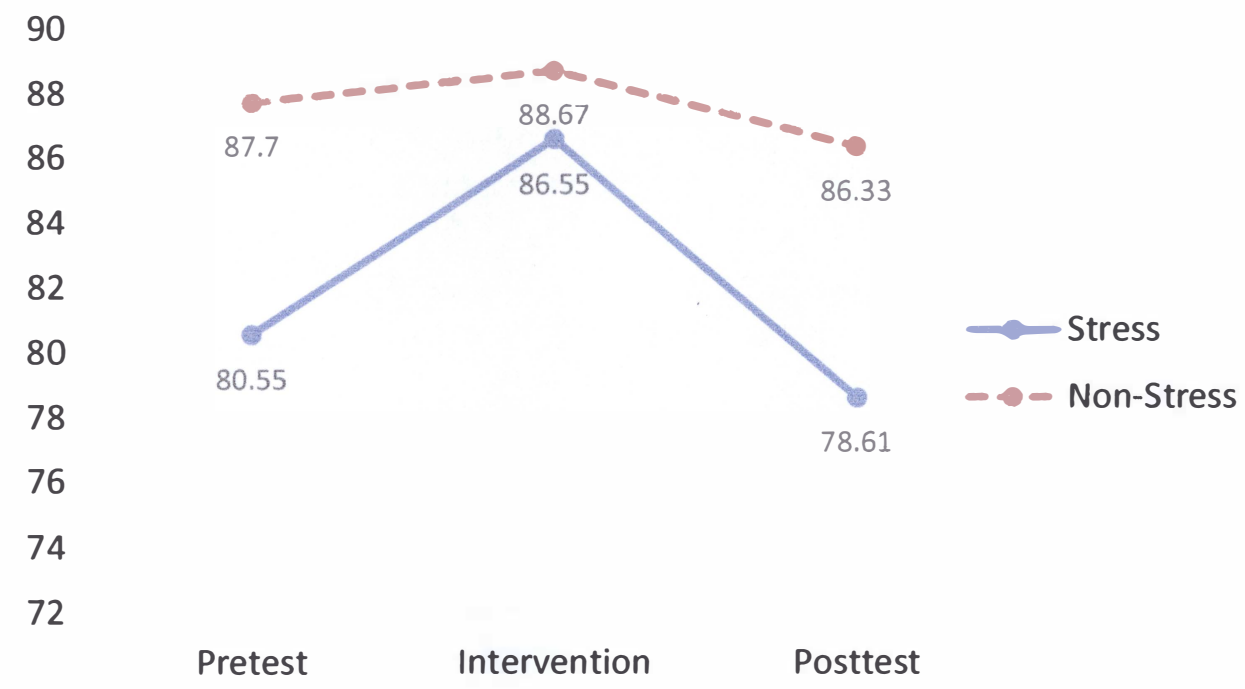

Figure 5. Heart rate change across change blindness tasks by condition.

This analysis was repeated, adding the median PSS scores as an additional between subject variable (see Table 8 ). There was not a significant three way interaction. In contrast, there was a significant interaction between the PSS median scores and the HR change of the change blindness tasks, $F(2,98)=3.65, p=.03, \eta_{p}{ }^{2}=.07$. Within subjects contrasts revealed this interaction to be a significant quadratic trend, $F(1,49)=6.37, p=$ $.02, \eta_{p}{ }^{2}=.12$. Participants with lower preexisting stress showed a higher HR during the intervention $(M=91.72, S D=24.83)$ than during the pretest $(M=87.43, S D=31.92)$ and the posttest $(M=78.55, S D=9.93)$. This result suggests that participants not exposed to chronic stress have a greater reaction to the intervention task, but that this difference is not related to which condition they are in. Additionally, a quadratic trend for the main effect of HR change was found, $F(1,49)=5.90, p=.02, \eta_{p}{ }^{2}=.11$. Regardless of stress level and condition, participants on average had an increase in HR during the intervention $(M=87.59, S D=19.20)$ relative to both the pretest $(M=84.06, S D=23.98)$ and the posttest $(M=82.39, S D=23.96)$, see figure 6. These results do not match the expectation 
that both acute stress and higher chronic stress would result in greater physiological reactions.

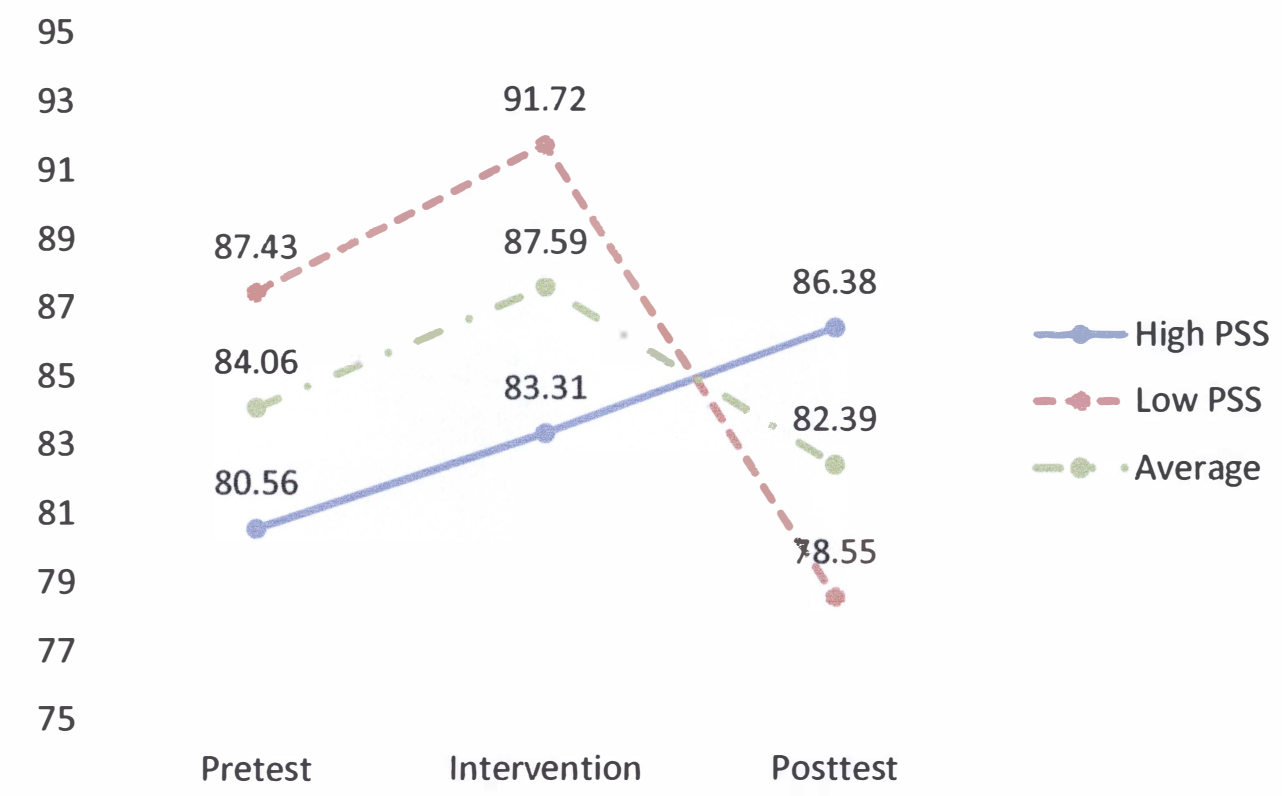

Figure 6. Heart rate changes over time during the change blindness tasks sorted by PSS level

\section{Additional Findings}

To test for the influence of the acute stress task on performance, a Pearson's $r$ correlation was calculated between the heart rate change during the intervention task and the number of errors made on the stress task. Individuals who had greater heart rate change during the intervention task also tended to make more errors on the stress inducing task, $r(27)=.35, p=.04$ (one-tailed). This analysis is further evidence that the stress inducing task had an effect on most participants.

A Pearson's $r$ correlation was calculated on the PSS scores and the current stress rating of participants. Individuals who had greater average scores on the PSS inventory also tended to report a higher current stress level, $r(52)=.65, p<.001$ (one-tailed). This correlation suggests that participants who perceived themselves as experiencing higher stress levels over the last month also felt greater stress at the time of the experiment. 


\section{Discussion}

The aim of the current study was to examine the impact of chronic and acute stressors on visual attention and heart rate. Specifically, this study examined sustainedattention, change blindness, and inattentional blindness, and how stress (preexisting and acute laboratory stress) affected performance on these measures of visual attention.

\section{Acute Lab Induced Stress}

Sustained Attention. It was predicted that performance on sustained attention tasks would be poorer following exposure to stress. Performance on the sustained attention tasks was measured by accuracy (the percentage of hits versus misses and errors) and reaction time. Analyses suggest that acute stress applied in the lab did not have a significant impact on the participants' performance at any time during the task. Previous research has shown that stressors often interfere without our ability to allocate our attention, including interference with filtering and processing information (Ellenbogen et al., 2002; Eysenck et al., 2007). It was expected that a similar effect would appear in the current study, and that exposure to stress would lead to an inability to devote attention resources toward the task. Contrary to expectation, there was a significant improvement in participants' accuracy when comparing the pretest and posttest performance. Likewise, participants' accuracy also increased across the blocks over time. These results suggest that participants`accuracy improved over the course of the sustained attention task, although participants' response times remained stable across the sustained attention tasks.

Additionally, participants often did not respond fast enough before the computer timed out, suggesting that the sustained attention task may have been too difficult, 
resulting in a floor effect. This is potentially related to the fast-paced nature of the task, as natural reaction time is likely slower than the task demands. It was common for participants to remark after completing the task that they felt it was very fast or that it was difficult to complete. Another potential confound is the sensitivity of the program in terms of time measurement, as there is the potential for a delay between the keyboard signal and the program recording the response. Together, these results suggest that the acute stress applied in lab was insufficiently intense to cause measureable impairments in attention.

In contrast to the expected vigilance decrement, modest improvements were seen across all blocks of the sustained attention task. Vigilance decrement research suggests that our attention naturally fades over the course of about fifteen minutes, or five minutes under mental stress (Warm et al., 2008), and the sustained attention tasks usually did not last much longer than five to six minutes. The lack of decline in performance could be related to the lack of extended time spent on the task, or it could be negated by the effect of participants' learning. Because the task was unfamiliar to participants, it is understandable that their initial performance would be poorer and that they would improve with continual performance and practice. In contrast to the hypotheses, the trend of improvement occurred in both the stress and non-stressed condition; mild acute stress does not seem to have a significant eff ect on maintaining attention. The improvement in performance could also be connected to an increase in neural activity related to acute stress, which has been shown to improve cognitive functioning (McEwen \& Sapolsky, 1995). The performance changes observed in the current study could be a product of the improvements in cognitive functioning under short term stress. A large body of research 
has shown that extended exposure to stress can damage the brain and important structures within (Lupien et al., 2009; McEwen. 2008; Segerstrom \& Miller, 2004) but it could be the case that the participants in this study have not experienced enough stress to exhibit the deficits related to these types of damage.

Change Blindness. It was expected that performance on change blindness tasks would decline after being exposed to a stress inducing task. Performance for the change blindness tasks was measured in terms of both accuracy and response time. Accuracy for the tasks was measured by the total number of attempts made before identifying the correct answer. This was indicated as a percentage. for example three total attempts including the correct answer was $33 \%$ accuracy. Any image pairs that were not responded to were considered to be inaccurate (or $0 \%$ ). Stress condition did not have a significant impact on the performance scores, similar to the sustained attention tasks. As was the case with the sustained attention tasks, accuracy improved over time, suggesting a similar practice effect. Although in the change blindness task there was no way to predict what the change would be, a participant could potentially learn search strategies to employ when completing the tasks. The overall results suggest that exposure to an acute stressor does not appear to interfere with our ability to observe changes in our environment.

Inattentional Blindness. The current study predicted that exposure to stress would lead to poorer performance on the inattentional blindness task, indicating an impairment in the ability to perceive unexpected stimuli. Rates of inattentional blindness were measured by their responses following the presentation of the critical stimulus. The majority of participants reported either not seeing the stimulus at all or provided an 
inaccurate description. Results of the chi-square analysis were not significant, suggesting that ability to perceive stimuli and acute stress may not be related. Although not significant in this relatively small sample, a greater proportion of participants in the nonstress condition were able to accurately report seeing the unexpected stimulus. It is possible that with a larger sample size a significant trend would appear. Although it may not be a dramatic effect, acute stressors may have an impact on our ability to perceive stimuli that we do not expect. Even if this were to only occur in low rates, this could have serious implications for our safety and performance in high-stress situations.

\section{Preexisting Chronic Stress}

Impact on Visual Attention. Analyses conducted on participants' median PSS scores for all tasks yielded mixed results regarding the hypothesis that preexisting stress has a negative ef fect on visual attention abilities. When examining the interaction between the PSS scores and time for the sustained attention accuracy, a significant difference became apparent between the participants with high versus low preexisting stress. Although all participants showed improvement over time, the participants who fell into the high PSS score group showed significantly less improvement than their counterparts. This suggests that chronic stress does have an impact on sustained attention capacity. These results mirror previous findings that individuals with PTSD, a large source of chronic stress. show difficulty with attention and encoding information (.J J Vasterling et al., 1998). Changes in response time for the sustained attention tasks was not significant. as participants only tended to vary by a matter of milliseconds. This held true regardless of both condition and PSS score. The lack of significant results for 
response time changes could be caused by the same difficulties mentioned previously, such as a lack of sensitivity in the measure or slow physical reactions of the participants.

For the change blindness results, despite no significant interactions occurring. some interesting trends did appear in the data. When separating participants by condition and comparing the response times of the pretest and the posttest by PSS score, participants with higher preexisting stress in the stress condition did not show improvements in their speed. Unlike participants with lower PSS scores and all participants in the non-stress condition, participants with high chronic stress showed a slowing in their performance despite initially having a faster initial reaction time compared to their lower PSS score counterparts. Additionally, higher preexisting stress participants in the control condition also showed faster overall response times on both change blindness tasks compared to their peers. Although the statistics are not significant, this trend could suggest that exposure to greater chronic stress could prime individuals to engage in search behaviors more often, which would allow them to observe the changes in their environment more quickly. Were this trend significant, it could provide some insight into the development of hypervigilance symptoms in individuals with exposure to trauma or who have PTSD. The decrease in response time of the high PSS individuals in the stress condition could suggest that adding acute stress to these participants interfered with the priming effect and reduced efficiency. This would align with the finding that PTSD has been shown to lead to greater sensitivity to interference (Vasterling et al., 1998), such as the attention disturbance cause by exposure to an acute stressor in this study. 
It does not appear to be the case that chronic stressors lead to an impairment in the ability to perceive unexpected stimuli. The low and high preexisting stress groups both showed similar distributions of participants who were and were not able to see the stimulus. Looking at all three measures of visual attention, it does not appear to be the case that chronic stress impairs all aspects. Instead, it seems as though preexisting stress had more subtle effects on different areas of attention. One consideration for the reason that the impacts of stress were not evident in the current study is that stress impacts many crucial areas of the brain (Weymar et al., 2012) and the diversity of this effect may manif est differently across individuals. While a change in attention abilities might be quickly apparent in some individuals, there are perhaps other impairments, such as memory deficits or changes to decision making, which may appear first. Because the length of the experiment was relatively short, it could be the case that not enough time elapsed for impairments in attention to appear in many individuals.

\section{Physiological Responses}

In other studies, monitoring heart rate has been an effective method of detecting a response to mentally stressful events (Choi \& Ricardo, 2009; Taelman, Vandeput, Spaepen, \& Huffel, 2008). However, analyzing the HR fluctuations during the current experiment yielded mixed results. When examining the HR changes over time for the sustained attention tasks, a significant quadratic trend was apparent when examining the changes over time between the stress and control conditions. Similarly, a significant quadratic trend was present in the HR change across the three time points of the change blindness tasks, although this was not related to stress condition. This result suggests that unlike the sustained attention tasks, participants in both conditions experienced an 
elevated HR during the intervention task regardless of whether the task was neutral or meant to induce stress.

It is difficult to draw conclusions from the results of the HR analyses for a number of reasons. Perhaps most importantly is the high degree of individual variability when examining physiological measures. Several participants exhibited significantly elevated HRs throughout participation without any clear reason. It could be that these elevations were just natural to the individual, that they responded to participation in general with stress, or that the HR monitor itself was not giving accurate readings. A high amount of individual variability in HR suggests that results gathered cannot easily be interpreted or generalized.

\section{Clinical Applications}

In the context of psychotherapy it is important to consider a range of factors that can contribute to the success of treatment. such as client engagement, dropout rates, and therapeutic alliance. The role that stress plays in mental health is a theme that influences treatment for a wide range of concerns. and is not one that should be overlooked when considering therapeutic approach and treatment goals. Disorders related to stress, specifically PTSD. Depression. and Anxiety, are not only some of the most common disorders. but they are also some of the highest instances of comorbidities (Dadić-Hero, Torić. Ružić, Medved, \& Graovac. 2009; Foa, 2009). One of the dilemmas in PTSD treatment specifically, is that many individuals who complete evidenced based therapies do not end care having achieved a meaningfill improvement in their symptoms and often must seek additional treatment (Cukor, Olden. Lee, \& Difede, 2010). Additionally, treatment of PTSD, including active treatment methods such as exposure, tend to have 
high rates of dropout (Imel, Laska, Jakupcak, \& Simpson, 2013). Because of this, it is especially important to ensure that additional factors such as the impact that stress may have on their ability to engage in treatment or to complete homework does not also interfere with treatment success.

The evidence found in the current study of the effects of stress. especially chronic or preexisting stress, suggest that therapists should take into account additional factors. One of the findings that has the most significant implications for psychotherapy is the negative impact that chronic stressors can have on sustained attention. Especially in disorders like PTSD. where exposure to stress is long-lasting, an individual's ability to maintain attention should be considered. Therapies that require clients to complete long homework tasks or follow lengthy instructions at home will likely show less success. Clients may struggle with remembering instructions or with having the attention span or patience to complete the assignments. This could lead to discouragement and negative responses from the therapist, which will in turn reduce retention rates for therapy. Psychotherapies which optimize in-session practice of skills and present focused work would likely be more beneficial for clients impacted by reduced attention capacities.

\section{Limitations and Future Directions}

Several limiting factors were present in the current study. Primary among them is the lack of variability in age. gender, or education in the sample utilized. The majority of participants were younger, Caucasian females and the sample was not representative of the desired population of non-clinical American adults. Because the pool from which participants were drawn was related to an introductory psychology course on campus, the majority of participants were college freshman between the ages of 18 and 19. This age 
range is typically a large adjustment period for many, as they are away from home for the first time and are beginning the process of adjusting to the expectations of college. For many of these individuals the transition from high school to post-secondary education can be difficult, due to increased demands and a lack of developed coping skills. This population has the potential to be under a great deal of stress already, and thus could potentially be performing at a level of impairment not measurable by the study due to a lack of fluctuation during participation. In contrast, it is also possible that participants in this age range have already learned how to adjust to the type of stressor applied to participants, and thus were not significantly impacted by the acute stressor.

An additional limitation of the acute stress applied was the length of time utilized in the study. The stress inducing task lasted for only ten minutes and completion of the stimulus presentation tasks continued immediately after. The lack of wait time between the stress induction and the tasks could have interfered with the impact of cortisol on the brain, as it typically takes anywhere from 10 to 30 minutes for cortisol to peak in the system following stress (Kirschbaum \& Hellhammer, 2000).

For future studies, a replication of the current study utilizing a larger and heterogeneous sample would be ideal. Beyond that, it would be beneficial to examine similar effects within a clinical population. Doing so would allow for a better conclusion about the impact of stress on visual attention following long term exposure. Ideally this information would be utilized to develop a treatment methodology that addressed concerns about visual attention abilities in relation to stress. A clinical trial comparing the efficacy of existing treatment styles which rely on different degrees of visual attention 
could be a beneficial first step in improving the treatment of disorders with high levels of stress exposure. 


\section{References}

Allan. J. L., Farquharson, B., Johnston. D. W., Jones, M. C., Choudhary, C. J., \& Johnston, M. (2014). Stress in telephone helpline nurses is associated with failures of concentration, attention and memory, and with more conservative referral decisions. British Journal of Psychology, 105, 200-213. http://doi.org/10.1111/bjop.12030

American Psychiatric Association. (2013). DSM 5. American Journal of Psychiatry. http://doi.org/1 0.1176/appi.books.9780890425596.744053

Baker, K. B., \& Kim, J. J. (2002). Effects of Stress and Hippocampal NMDA Receptor Antagonism on Recognition Memory in Rats. Learning \& Memory, 9, 58-65. http://doi.org/10.1 101/lm.46102

Barlow-Ogden, K., \& Poynter, W. (2012). Mild traumatic brain injury and posttraumatic stress disorder: investigation of visual attention in Operation Iraqi Freedom/Operation Enduring Freedom veterans. Journal of Rehabilitation Research and Development. $19(7), 1101-14$.

http://doi.org/10.1682/JRRD.2010.09.0188

Booth, R., \& Sharma, D. (2009). Stress reduces attention to irrelevant information: Evidence from the Stroop task. Motivation and Emotion, 33, 412-418. http://doi.org/10.1007/sl 1031-009-9141-5

Campbell, T. S., Labelle, L. E., Bacon, S. L., Faris, P., \& Carlson, L. E. (2012). Impact of Mindfulness-Based Stress Reduction (MBSR) on attention, rumination and resting blood pressure in women with cancer: A waitlist-controlled study. Journal 
of Behavioral Medicine, 35(November 2006), 262-271.

http://doi.org/10.1007/s10865-011-9357-1

Chajut, E., \& Algom. D. (2003). Selective attention improves under stress: implications for theories of social cognition. Journal of Personality and Social Psychology, 85(2), 231-248. http://doi.org/10.1037/0022-3514.85.2.231

Choi, J., \& Ricardo, G. O. (2009). Using heart rate monitors to detect mental stress. Proceedings - 2009 6th International Workshop on Wearable and Implantable Body Sensor Networks, BSN 2009, 219-223. http://doi.org/l 0.1109/BSN.2009.13

Cohen, S. (1994). Perceived Stress Scale. Psychology, (February), 1-3. Retrieved from http://www.mindgarden.com/products/pss.htm

Cohen, S., Janicki-Deverts, D., \& Miller, G. E. (2007). Psychological stress and disease. Journal of the American Medical Association. 298, 1685-1687. Retrieved from http://www.psy.cmu.edu/ scohen/JAMA_2007_Psy_Stress_Disease.pdf

Cohen, S., Kamarck, T., \& Mermelstein, R. (1983). A global measure of perceived stress. Journal of Health and Social Behavior, 24(4), 385-396.

Cukor, J., Olden. M., Lee, F., \& Difede. J. (2010). Evidence-based treatments for PTSD, new directions, and special challenges. Annals of the New York Academy of Sciences, 1208(1), 82-89. http://doi.org/10.1111/j.1749-6632.2010.05793.x

Dadić-Hero, E., Torić, I.. Ružić, K.. Medved, P., \& Graovac, M. (2009). Comorbidity - A troublesome factor in PTSD treatment. Psychiatria Danubina, 21(3), 420-424.

Dennis, M. K., Field, A. S., Burai, R., Ramesh, C., Whitney, K.. Bologa, C. G., ... Prossnitz, E. R. (2004). Attention, learning, and memory in Posttraumatic Stress 
Disorder. Journal of Traumatic Stress, 17(1), $41-46$.

http://doi.org/10.1016/j.jsbmb.2011.07.002.Identification

Ellenbogen, M. A, Schwartzman, A. E., Stewart, J., \& Walker, C.-D. (2002). Stress and selective attention: the interplay of mood, cortisol levels, and emotional information processing. Psychophysiology, 39, 723-732. http://doi.org/10.1017/S0048577202010739

Eysenck. M. W., Derakshan, N., Santos, R., \& Calvo, M. G. (2007). Anxiety and cognitive performance: attentional control theory. Emotion (Washington, D.C.), 7(2), 336-353. http://doi.org/10.1037/1528-3542.7.2.336

Fitzgerald, R. J., Oriet, C., \& Price, H. L. (2014). Change blindness and eyewitness identification: Effects on accuracy and confidence. Legal and C'riminological Psychology, 2. http://doi.org/10.1111/lcrp.12044

Foa, E. (2009). Treatment of PTSD and Comorbid Disorders. In Effective Treatments for PTSD (Second, pp. 606-613). New York, NY: The Guilford Press.

Hancock, P. A, \& Warm, J. S. (1989). A dynamic model of stress and sustained attention. Human Factors: The Journal of the Human Factors and Ergonomics Society. Retrieved from http://www.ncbi.nlm.nih.gov/pubmed/14552346

Imel, Z. E., Laska, K., Jakupcak, M., \& Simpson, T. L. (2013). Meta-analysis of dropout in treatments for posttraumatic stress disorder. Journal of Consulting and Clinical Psychology, 8I(3), 394-404. http://doi.org/10.1037/a0031474

Jackson, J. D., \& Balota, D. A. (2012). Mind-wandering in younger and older adults: Converging evidence from the sustained attention to response task and reading for 
comprehension. Psychology and Aging, 27(1), 106-119.

http://doi.org/10.1037/a0023933

Kirschbaum, C., \& Hellhammer, D. H. (2000). Salivary Cortisol. Encyclopedia of Stress.

Kirschbaum, C., Pirke, K. M., \& Hellhammer, D. H. (1993). The "Trier Social Stress

Test"--a tool for investigating psychobiological stress responses in a laboratory setting. Neuropsychobiology. http://doi.org/119004

Lee, E. H. (2012). Review of the psychometric evidence of the perceived stress scale. Asian Nursing Research. http://doi.org/10.1016/j.anr.2012.08.004

Levin, D. T., Drivdahl, S. B., Momen, N., \& Beck, M. R. (2002). False predictions about the detectability of visual changes: The role of beliefs about attention, memory, and the continuity of attended objects in causing change blindness blindness. Consciousness and Cognition, I 1(4), 502 - 527. http://doi.org/10.1016/S10538100(02)00020-X

Levin, D. T., Momen, N., Drivdahl, S. B., \& Simons, D. J. (2000). Change blindness blindness: The metacognitive error of overestimating change-detection ability. Visual Cognition, 7, 397--412. http://doi.org/10.1080/135062800394865

Liston. C., Miller, M. M., Goldwater, D. S., Radley, J. J., Rocher, A. B., Hof, P. R., ... McEwen, B . S. (2006). Stress-induced alterations in prefirontal cortical dendritic morphology predict selective impairments in perceptual attentional set-shifting. The Journal of Neuroscience : The ()fficial Journal of the Society for Neuroscience, 26(30), 7870-7874. http://doi.org/10.1523/JNEUROSCI.118406.2006 
Lupien, S. (2013). How to measure stress in humans. Stresshumain. C'a. 1-28. Retrieved from http://www.stresshumain.ca/documents/pdf/SalivaLab/HOW TO

\section{MEASURE STRESS_CSHS.pdf}

Lupien. S. J., Maheu, F.. Tu, M.. Fiocco. A., \& Schramek, T. E. (2007). The effects of stress and stress hormones on human cognition: Implications for the field of brain and cognition. Brain and ('ognition, 65, 209-237. http://doi.org/10.1016/j.bandc.2007.02.007

Lupien. S. J., McEwen, B. S., Gunnar. M. R., \& Heim, C. (2009). Effects of stress throughout the lifespan on the brain. behaviour and cognition. Nature Reviews. Neuroscience, 10(junE), 434-445. http://doi.org/10.1038/nrn2639

Mack, A., \& Rock, 1. (1998). Inattentional blindness. MIT Press/Bradford Books Series in C'ognitive Psychology, Inattentional blindness. xiv, 273. http://doi.org/10.1016/j.aorn.2010.03.011

Masuda. T., \& Nisbett, R. E. (2006). Culture and change blindness. Cognitive Science, 30. 381-399. http://doi.org/10.1207/s15516709cog0000_63

Mathôt. S.. Schreij. D.. \& Theeuwes, J. (2012). OpenSesame: an open-source. graphical experiment builder for the social sciences. Behavior Research Methods, ff(2), 314-24. http://doi.org/10.3758/s13428-011-0168-7

McCabe. R. E., \& Milosevic. I. (2015). Phobias: The Psychology of Irrational Fear. ABC-CLIO. Retrieved from https://books.google.com/books?hl=en\&lr=\&id=1 BfYBgAAQBAJ\&pgis=1

McEwen, B. S. (2008). Central effects of stress hormones in health and disease: Understanding the protective and damaging effects of stress and stress mediators. 
European Journal of Pharmacology, 583.174-185.

http://doi.org/10.1016/j.ejphar.2007.11.071

McEwen. B. S., \& Sapolsky, R. M. (1995). Stress and cognitive function. Current Opinion in Neurohiology., 5. 205-216.

Mogg. K., Mathews, A., Bird, C.. \& Macgregor-Morris, R. (1990). Effects of stress and anxiety on the processing of threat stimuli. Journal of Personality and Social Psychology, 59(6), 1230-1237. http://doi.org/10.1037/0022-3514.59.6.1230

Nesse, R. M., Bhatnagar, S., \& Young, E. A. (2007). Evolutionary origins and functions of the stress response. Retrieved March 20, 2015, from http://wwwpersonal.umich.edu/ nesse/Articles/Nesse-EvolStressResponse-2007.PDF

Payne, J. D., Nadel, L., Allen, J. J. B., Thomas, K. G. F.. \& Jacobs, W. J. (2002). The effects of experimentally induced stress on false recognition. Memory (Hove, England), 10(1), 1-6. http://doi.org/1 0.1080/09658210143000119

Posner, M., \& Peterson, S. (1989). The attention system of the human brain. Annual Review of Neuroscience, 13.25-42. Retrieved from http://www.dtic.mil/dtic/tr/fulltext/u2/a206157.pdf

Rensink, R. A., O`Regan, J. K., \& Clark, J. J. (1996). To see or not to see: The need for attention to perceive changes in scenes. Investigative ()phthalmology and Visual Science, 37(3). http://doi.org/10.1111/j.1467-9280.1997.tb00427.x

Schlotz, W., Yim, 1. S., Zoccola. P. M., Jansen, L.. \& Schulz, P. (2011). The Perceived Stress Reactivity Scale: measurement invariance, stability, and validity in three countries. Psychological Assessment. 23(1), 80-94.

http://doi.org/1 0.1037/a0021148 
Segerstrom, S. C., \& Miller, G. E. (2004). Psychological stress and the human immune system: A meta-analytic study of 30 years of inquiry. Psychological Bulletin, 130(4), 601-630. http://doi.org/10.1016/j.biotechadv.2011.08.021.Secreted

Simons, D. J. (2000). Attentional capture and inattentional blindness. Trends in Cognitive Sciences, 4(4), 147-155. http://doi.org/10.1016/S1 364-6613(00)01455-8

Simons, D. J., \& Ambinder, M. S. (2005). Change blindness: Theory and consequences. Current Directions in Psychological Science, 14, 44-48. http://doi.org/10.1111/j.0963-7214.2005.00332.x

Simons, D. J., \& Chabris, C. F. (1999). Gorillas in our midst: Sustained inattentional blindness for dynamic events. Perception, 28, 1059-1074.

Simons, D. J., Franconeri, S. L., \& Reimer, R. L. (2000). Change blindness in the absence of a visual disruption. Perception, 29, 1143-1154. http://doi.org/10.1068/p31 04

Simons, D. J.. \& Levin, D. T. (1997). Change blindness. Trends in Cognitive Sciences. http://doi.org/1 0.1016/S1364-6613(97)01080-2

Smallwood. J., \& Schooler, J. (2006). The Restless Mind. Psychological Bulletin. 132, 946-958.

Taelman, J., Vandeput, S., Spaepen, A., \& Huffel, S. Van. (2008). Influence of mental stress on heart rate and heart rate variability. IFMBE Proceedings 22, 13661369. http://doi.org/10.1007/978-3-540-89208-3_324

Thomson, D. R., Besner, D., \& Smilek, D. (1948). A resource-control account of sustained attention: Evidence from mind-wandering and vigilance paradigms. 
Perspectives on Psychological Science.

http://doi.org/10.1177/1745691614556681

Vasterling, J. J., Brailey, K., Constans, J. I., \& Sutker, P. B. (1998). Attention and memory dysfunction in posttraumatic stress disorder. Neuropsychology, 12(1), 125-133. http://doi.org/10.1037/0894-4105.12.1.125

Vasterling, J. J., Brailey, K., Proctor, S. P., Kane, R., Heeren, T., \& Franz, M. (2012). Neuropsychological outcomes of mild traumatic brain injury, post-traumatic stress disorder and depression in Iraq-deployed US Army soldiers. British Journal of Psychiatry, 201(3), 186-192. http://doi.org/10.1192/bjp.bp.111.096461

Vasterling, J. J., Proctor, S. P., Amoroso, P., Kane, R., Heeren, T., \& White, R. F. (2006). Neuropsychological outcomes of Army personnel following deployment to the Iraq War. Journal of the American Medical Association, 296(5), 519-529. http://doi.org/10.1001/jama.296.5.519

Warm, J. S., Parasuraman, R., \& Matthews, G . (2008). Vigilance requires hard mental work and is stressful. Human Factors, 50(3), 433-441. http://doi.org/10.1518/001872008X312152

Weymar, M., Schwabe, L., Löw, A., \& Hamm, A. O. (2012). Stress Sensitizes the Brain: Increased Processing of Unpleasant Pictures after Exposure to Acute Stress. Journal of Cognitive Neuroscience, 24, 1511-1518. http://doi.org/10.1162/jocn_a_00174

Zephyr (2013). Zephyr Omnisense Analysis [Computer software]. Annapolis, MD: Zephyr Technology Corporation. 
Summary Tables

Table 1

Demographic Characteristics Summary Table

\begin{tabular}{clll}
\hline \multicolumn{2}{c}{ Characteristic } & $n$ & $\%$ \\
\hline Age & 18 & & \\
& 19 & 23 & 42.6 \\
& 20 & 18 & 33.3 \\
Gender & 21 & 3 & 18.5 \\
& & & 5.6 \\
& Male & 39 & 72.2 \\
Education & Female & 15 & 27.8 \\
& Other/Prefer Not to Say & 0 & 0 \\
& Freshman & 37 & 68.5 \\
& Sophomore & 13 & 24.1 \\
& Junior & 3 & 5.6 \\
& Senior & 1 & 1.9 \\
& Other & 0 & 0 \\
& Caucasian & 33 & 61.1 \\
& African-American & 13 & 24.1 \\
& Hispanic & 3 & 5.6 \\
& Asian/Pacific lslander & 0 & 0 \\
& Other & 5 & 9.3 \\
\hline
\end{tabular}


Table 2

ANOV A Summary Table Sustained Attention Accuracy by Time and Block

\begin{tabular}{|c|c|c|c|c|c|c|c|}
\hline $\begin{array}{l}\text { Source of } \\
\text { Variance }\end{array}$ & $S S$ & $d f$ & $M S$ & $F$ & $P$ & $\eta_{p}{ }^{2}$ & Power \\
\hline \multicolumn{8}{|l|}{ Between } \\
\hline \multicolumn{8}{|l|}{ Subjects } \\
\hline Condition & .12 & 1 & .12 & .72 & .40 & .01 & .13 \\
\hline Error & 8.30 & 51 & .16 & & & & \\
\hline \multicolumn{8}{|l|}{ Within } \\
\hline \multicolumn{8}{|l|}{ Subjects } \\
\hline $\begin{array}{r}\text { Pretest } \\
\text { Posttest }\end{array}$ & .77 & 1 & .77 & 22.86 & $.000^{* *}$ & .31 & 1.00 \\
\hline Error & 1.71 & 51 & .03 & & & & \\
\hline Block & .13 & 2 & .06 & 6.53 & $.002 *$ & .11 & .90 \\
\hline Error & 1.01 & 102 & .01 & & & & \\
\hline Block $x$ & & & & & & & \\
\hline $\begin{array}{l}\text { Condition } \\
\text { Interaction }\end{array}$ & .02 & 2 & .01 & 1.00 & .37 & .02 & .22 \\
\hline Error & 1.01 & 102 & .01 & & & & \\
\hline PrePost $\mathrm{x}$ & & & & & & & \\
\hline $\begin{array}{r}\text { Block } \\
\text { Interaction }\end{array}$ & .01 & 2 & .003 & .45 & .64 & .01 & .12 \\
\hline PrePost $\mathrm{x}$ & & & & & & & \\
\hline $\begin{array}{r}\text { Block x } \\
\text { Condition } \\
\text { Interaction }\end{array}$ & .01 & 2 & .004 & .51 & .60 & .01 & .13 \\
\hline Error & .78 & 102 & .01 & & & & \\
\hline
\end{tabular}

Table 3

ANOVA Summary Table ('hange Blindness Accuracy by Time and C'ondition

$\begin{array}{lccccccc}\begin{array}{c}\text { Source of } \\ \text { Variance }\end{array} & S S & d f & M S & F & P & \eta_{p}{ }^{2} & \text { Power } \\ \text { Between } \\ \text { Subjects }\end{array}$


Table 4

ANOVA Summary Table Sustained Attention Accuracy by Time and Block by PSS score

$\begin{array}{llllllll}\text { Source of } & S S & d f & M S & F & P & \eta_{p}{ }^{2} & \text { Power }\end{array}$

Variance

Between

Subjects

\begin{tabular}{|c|c|c|c|c|c|c|c|}
\hline Condition & .10 & 1 & .10 & .62 & .434 & .01 & .12 \\
\hline PSS Median & .06 & 1 & .03 & .36 & .55 & .01 & .10 \\
\hline $\begin{array}{r}\text { Condition } \mathrm{x} \\
\text { PSS }\end{array}$ & .06 & 1 & .06 & .39 & .54 & .01 & .10 \\
\hline Error & 8.18 & 49 & .17 & & & & \\
\hline
\end{tabular}

Within

Subjects

\begin{tabular}{|c|c|c|c|c|c|c|c|}
\hline Pre/Post & .76 & 1 & .75 & 24.96 & $.000 * * *$ & .34 & 1.00 \\
\hline $\begin{array}{l}\text { Pre/Post } \mathrm{x} \\
\text { Condition }\end{array}$ & .01 & 1 & .01 & .27 & .61 & .01 & .08 \\
\hline Pre/Post x PSS & .17 & 1 & .17 & 5.68 & $.02 *$ & .10 & .65 \\
\hline $\begin{array}{r}\text { PrePost } x \text { PSS } \\
\text { x Condition }\end{array}$ & .05 & 1 & .05 & 1.69 & .20 & .03 & .25 \\
\hline Error (PrePost) & 1.49 & 49 & .30 & & & & \\
\hline Block & .13 & 2 & .06 & 6.41 & $.002^{* *}$ & .12 & .90 \\
\hline $\begin{array}{r}\text { Block } \mathrm{x} \\
\text { Condition }\end{array}$ & .02 & 2 & .01 & 1.04 & .36 & .02 & .23 \\
\hline $\begin{array}{r}\text { Block x PSS } \\
\text { Block x }\end{array}$ & .01 & 2 & .003 & .33 & .72 & .01 & .10 \\
\hline $\begin{array}{r}\text { Condition } \mathrm{x} \\
\text { PSS }\end{array}$ & .03 & 2 & .02 & 1.49 & .23 & .03 & .31 \\
\hline Error (Block) & .97 & 98 & .01 & & & & \\
\hline $\begin{array}{r}\text { Pre/Post } \mathrm{x} \\
\text { Block }\end{array}$ & .01 & 2 & .003 & .45 & .64 & .01 & .12 \\
\hline $\begin{array}{r}\text { PrePost } \mathrm{x} \\
\text { Block } \mathrm{x} \\
\text { Condition }\end{array}$ & .01 & 2 & .004 & .50 & .61 & .10 & .13 \\
\hline $\begin{array}{r}\text { Pre/Post x } \\
\text { Block x PSS } \\
\text { Pre/Post x }\end{array}$ & .01 & 2 & .01 & .83 & .44 & .02 & .19 \\
\hline $\begin{array}{r}\text { Block } x \\
\text { Condition } x \\
\text { PSS }\end{array}$ & .004 & 2 & .002 & .26 & .77 & .01 & .09 \\
\hline $\begin{array}{r}\text { Error (Pre/Post } \\
\times \text { Block) }\end{array}$ & .76 & 98 & .01 & & & & \\
\hline
\end{tabular}


Table 5

ANOVA Summary Table Change Blindness Accuracy by Time and Condition by PSS level

$\begin{array}{rccccccc}\begin{array}{l}\text { Source of } \\ \text { Variance } \\ \text { Between }\end{array} & S S & d f & M S & F & P & \eta_{p}{ }^{2} & \text { Power } \\ \begin{array}{r}\text { Uubjects } \\ \text { Condition }\end{array} & .001 & 1 & .001 & .02 & .88 & .00 & .05 \\ \text { PSS } & .02 & 1 & .02 & .51 & .48 & .01 & .11 \\ \text { Condition x } & .04 & 1 & .04 & 1.04 & .31 & .02 & .17 \\ \text { PSS } & .11 & & & & & \\ \text { Error } & 1.69 & 50 & .03 & & & & \end{array}$

Within

Subjects

$\begin{array}{rccccccc}\text { Pretest Posttest } & .06 & 1 & .06 & 4.66 & .04 * & .09 & .56 \\ \begin{array}{r}\text { PrePost x } \\ \text { Condition }\end{array} & .003 & 1 & .003 & .24 & .63 & .01 & .08 \\ \text { PrePost x PSS } & .05 & 1 & .05 & 3.59 & .06 & .07 & .46 \\ \begin{array}{r}\text { PrePost x } \\ \text { Condition x }\end{array} & .01 & 1 & .01 & .37 & .55 & .01 & .09 \\ \begin{array}{r}\text { PSS } \\ \text { Error }\end{array} & .62 & 50 & .01 & & & & \\ \text { Note. }{ }^{*} p=.05, * * p<.001 & & & & & & \end{array}$

Table 6

ANOVA Summary Table Heart Rate Change in Sustained Attention Tasks by Condition

$\begin{array}{llllllll}\begin{array}{c}\text { Source of } \\ \text { Variance }\end{array} & S S & d f & M S & F & P & \eta_{p}{ }^{2} & \text { Power } \\ \text { Between } & & & & & & & \end{array}$

Between

Subjects

$\begin{array}{rccccccc}\text { Condition } & 1629.04 & 1 & 1629.04 & 1.22 & .27 & .02 & .19 \\ \text { Error } & 68059.64 & 51 & 1334.50 & & & & \end{array}$

Within

Subjects

$\begin{array}{rccccccc}\text { HR Change } & 40.76 & 2 & 20.38 & .26 & .77 & .01 & .09 \\ \begin{array}{rccc}\text { HR Change } \\ \text { x Condition }\end{array} & 388.36 & 2 & 194.18 & 2.45 & .09 & .05 & .48 \\ \text { Error } & 8081.40 & 102 & 79.23 & & & & \end{array}$


Within Subject Contrast Heart Rate C'hange in Sustained Attention Tasks by Condition

$\begin{array}{lccccccc}\begin{array}{l}\text { Source of } \\ \text { Variance }\end{array} & S S & d f & M S & F & P & \eta_{p}{ }^{2} & P \text { Power } \\ \text { HR Change } & 40.75 & 1 & 40.75 & .61 & .44 & .01 & .12 \\ \begin{array}{l}\text { HR Change } \\ \text { x Condition }\end{array} & 363.454 & 1 & 363.454 & 5.432 & .02 * & .10 & .63 \\ \begin{array}{l}\text { Error } \\ \text { 3 }\end{array} 412.46 & 51 & 66.91 & & & & \\ \text { Note. }{ }^{*} p=.05\end{array}$

Table 7

ANOVA Summary Table Heart Rate C'hange in ('hange Blindness Tasks by C'ondition

\begin{tabular}{|c|c|c|c|c|c|c|c|}
\hline $\begin{array}{l}\text { Source of } \\
\text { Variance } \\
\text { Between } \\
\text { Subjects }\end{array}$ & $S S$ & $d f$ & $M S$ & $F$ & $P$ & $\eta_{p}^{2}$ & Power \\
\hline $\begin{array}{l}\text { Condition } \\
\text { Error } \\
\text { Within } \\
\text { Subjects }\end{array}$ & $\begin{array}{c}1275.36 \\
45932.83\end{array}$ & $\begin{array}{c}1 \\
51\end{array}$ & $\begin{array}{c}1275.36 \\
900.64\end{array}$ & 1.12 & .21 & .03 & .22 \\
\hline HR Change & 729.86 & 2 & 364.93 & 1.18 & .31 & .02 & .25 \\
\hline $\begin{array}{l}\text { HR Change } \\
x \text { Condition }\end{array}$ & 251.05 & 2 & 125.52 & .41 & .37 & .01 & .11 \\
\hline $\begin{array}{c}\text { Error } \\
\text { Note. }{ }^{*} p=.05\end{array}$ & $31449 . .55$ & 102 & 308.33 & & & & \\
\hline \multicolumn{8}{|c|}{ Within Subject Contrast Heart Rate Change in C'hange Blindness Tasks by Condition } \\
\hline $\begin{array}{l}\text { Source of } \\
\text { Variance }\end{array}$ & $S S$ & $d f$ & $M S$ & $F$ & $P$ & $\eta_{p}^{2}$ & Power \\
\hline IIR Change & 657.08 & 1 & 657.08 & 5.59 & $.02 *$ & .10 & .64 \\
\hline $\begin{array}{l}\text { HR Change } \\
\mathrm{x} \text { Condition }\end{array}$ & 248.914 & 1 & 248.91 & 2.12 & .15 & .04 & .30 \\
\hline $\begin{array}{c}\text { Error } \\
\text { Note. }{ }^{*} p=.05\end{array}$ & 5990.71 & 51 & 117.47 & & & & \\
\hline
\end{tabular}


Table 8

ANOVA Summary Table Heart Rate ('hange in ('hange Blindness Tasks by C'ondition and PSS

\begin{tabular}{|c|c|c|c|c|c|c|c|}
\hline $\begin{array}{l}\text { Source of } \\
\text { V'ariance }\end{array}$ & $S S$ & $d f$ & $M S$ & $F$ & $P$ & $\eta_{p}^{2}$ & Power \\
\hline \multirow{2}{*}{\multicolumn{8}{|c|}{$\begin{array}{l}\text { Between } \\
\text { Subjects }\end{array}$}} \\
\hline & & & & & & & \\
\hline Condition & 1275.36 & 1 & 1275.36 & 1.12 & .21 & .03 & .22 \\
\hline PSS & 277.13 & 1 & 277.13 & .30 & .59 & .01 & .08 \\
\hline $\begin{array}{r}\text { Condition } \mathrm{x} \\
\text { PSS }\end{array}$ & 311.425 & 1 & 311.425 & .34 & .57 & .01 & .09 \\
\hline \multicolumn{8}{|l|}{$\begin{array}{l}\text { Within } \\
\text { Subjects }\end{array}$} \\
\hline HR Change & 704.21 & 2 & 352.11 & 1.20 & .31 & .02 & .26 \\
\hline $\begin{array}{l}\text { HR Change } \\
x \text { Condition }\end{array}$ & 237.73 & 2 & 118.87 & .40 & .67 & .01 & .11 \\
\hline $\begin{array}{r}\text { HR Change } \\
\times \text { PSS }\end{array}$ & 2147.07 & 2 & 1073.53 & 3.65 & $.02 *$ & .07 & .67 \\
\hline $\begin{array}{r}\text { HR Change } \\
\text { x Condition } \\
\text { x PSS }\end{array}$ & 515.32 & 2 & 257.67 & .88 & .42 & .02 & .20 \\
\hline $\begin{array}{l}\text { Error } \\
\text { Note. }{ }^{*} p=.0\end{array}$ & 28821.68 & 98 & 294.10 & & & & \\
\hline \multicolumn{8}{|c|}{ Within Subject Contrast Heart Rate Change in Change Blindness Tasks by C'ondition } \\
\hline $\begin{array}{l}\text { Source of } \\
\text { Variance }\end{array}$ & $S S$ & $d f$ & $M S$ & $F$ & $P$ & $\eta_{p}^{2}$ & Power \\
\hline HR Change & 636.45 & 1 & 636.45 & 5.90 & $.02 *$ & .11 & .66 \\
\hline $\begin{array}{l}\text { HR Change } \\
x \text { Condition }\end{array}$ & 236.38 & 1 & 236.38 & 2.19 & .15 & .12 & .31 \\
\hline $\begin{array}{r}\text { HR Change } \\
\times \text { PSS }\end{array}$ & 686.67 & 1 & 686.67 & 6.37 & $.02 *$ & .12 & .70 \\
\hline $\begin{array}{r}\text { HR Change } \\
\times \text { Condition } \\
\times \text { PSS }\end{array}$ & 22.73 & 1 & 22.73 & .21 & .65 & .004 & .07 \\
\hline $\begin{array}{c}\text { Error } \\
\text { Note. }{ }^{*} p=.0\end{array}$ & 5285.61 & 49 & 107.87 & & & & \\
\hline
\end{tabular}




\section{Appendix A}

Age:

Gender: $M \quad F$

Year in School: Freshman Sophomore Junior Senior Other

Ethnicity: Caucasian African American Hispanic Asian/Pacific Islander

Other

How would you rate your current level of stress?

\begin{tabular}{ccccccc} 
Not at all stressed & Mild & & Fairly Stressed & & Overwhelmed \\
\hline 1 & 2 & 3 & 4 & 5 & 6 & 7
\end{tabular}

The following questions ask you about your thoughts or feelings during the last month.

In each case, you will be circling how often you felt or thought a certain way.

$0=$ Never $\quad 1=$ Almost Never $\quad 2=$ Sometimes $\quad 3=$ Fairly Often $\quad 4=$ Very

Often

1. In the last month, how often have you

been upset because of something that happened unexpectedly?

$\begin{array}{lllll}0 & 1 & 2 & 3 & 4\end{array}$

2. In the last month, how often have you

felt that you were unable to control the

$\begin{array}{lllll}0 & 1 & 2 & 3 & 4\end{array}$

important things in your life?

3. In the last month, how oft en have you

felt nervous and "stressed"?

$\begin{array}{lllll}0 & 1 & 2 & 3 & 4\end{array}$

4. In the last month, how often have you

felt confident about your ability to handle

your personal problems?

5. In the last month, how of ten have you

felt that things were going your way?

$\begin{array}{lllll}0 & 1 & 2 & 3 & 4\end{array}$ 
6. In the last month, how often have you found that you could not cope with all the things that you had to do?

7. In the last month, how often have you been able to control irritations in your $\begin{array}{lllll}0 & 1 & 2 & 3 & 4\end{array}$ life?

8. In the last month, how often have you felt that you were on top of things?

$\begin{array}{lllll}0 & 1 & 2 & 3 & 4\end{array}$

9. In the last month, how often have you been angered because of things that were outside of your control?

10. In the last month, how often have you felt difficulties were piling up so high that

$\begin{array}{lllll}0 & 1 & 2 & 3 & 4\end{array}$
you could not overcome them? 


\section{Appendix B}

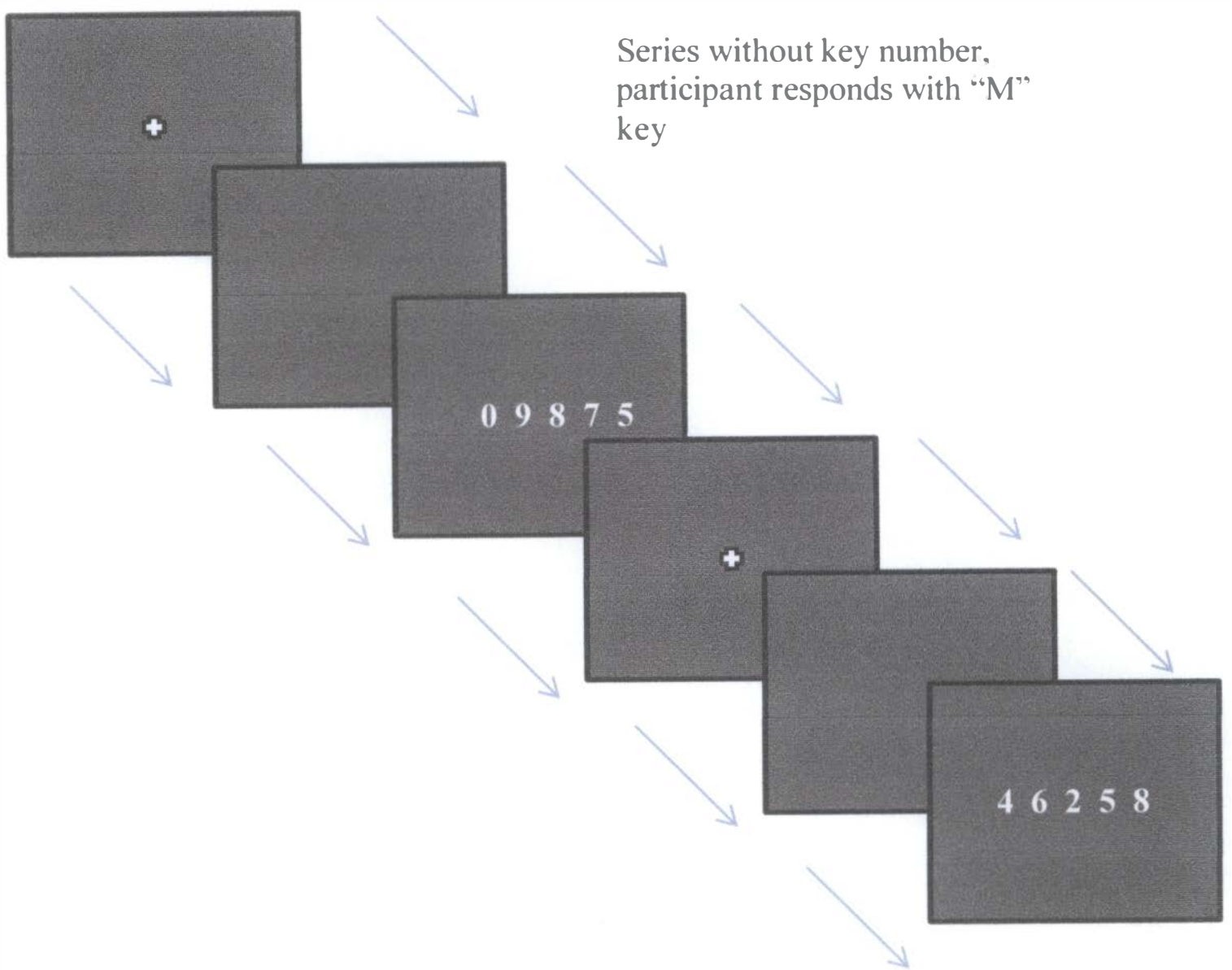

Each block contains 50 sets of randomly generated numbers

Series with key number, participant responds with "V" key

The task contains 3 blocks, with a rest period between each one 


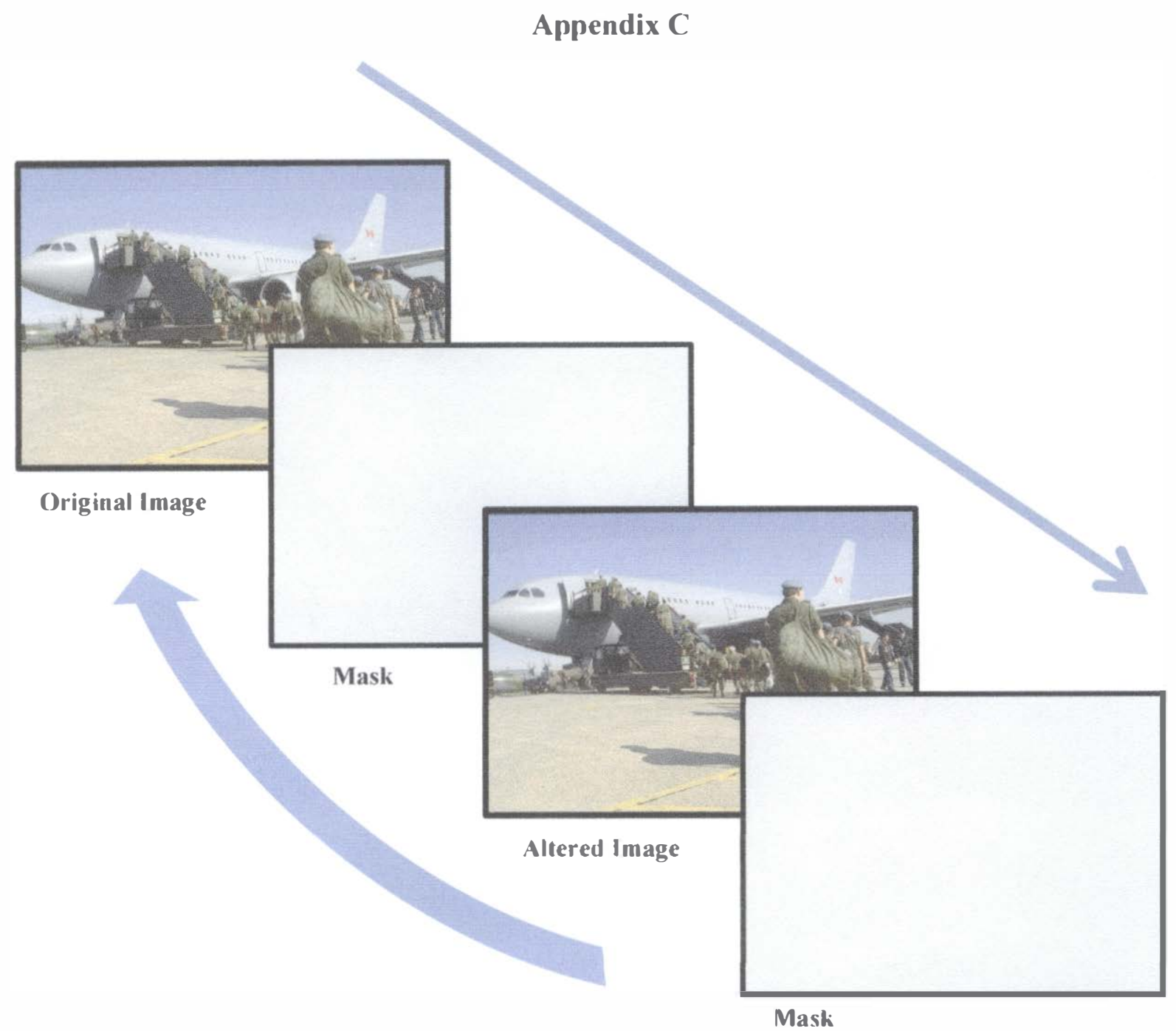

The task contains 10 image pairs, which cycle either until a correct change is identified or 15 cycles has occurred
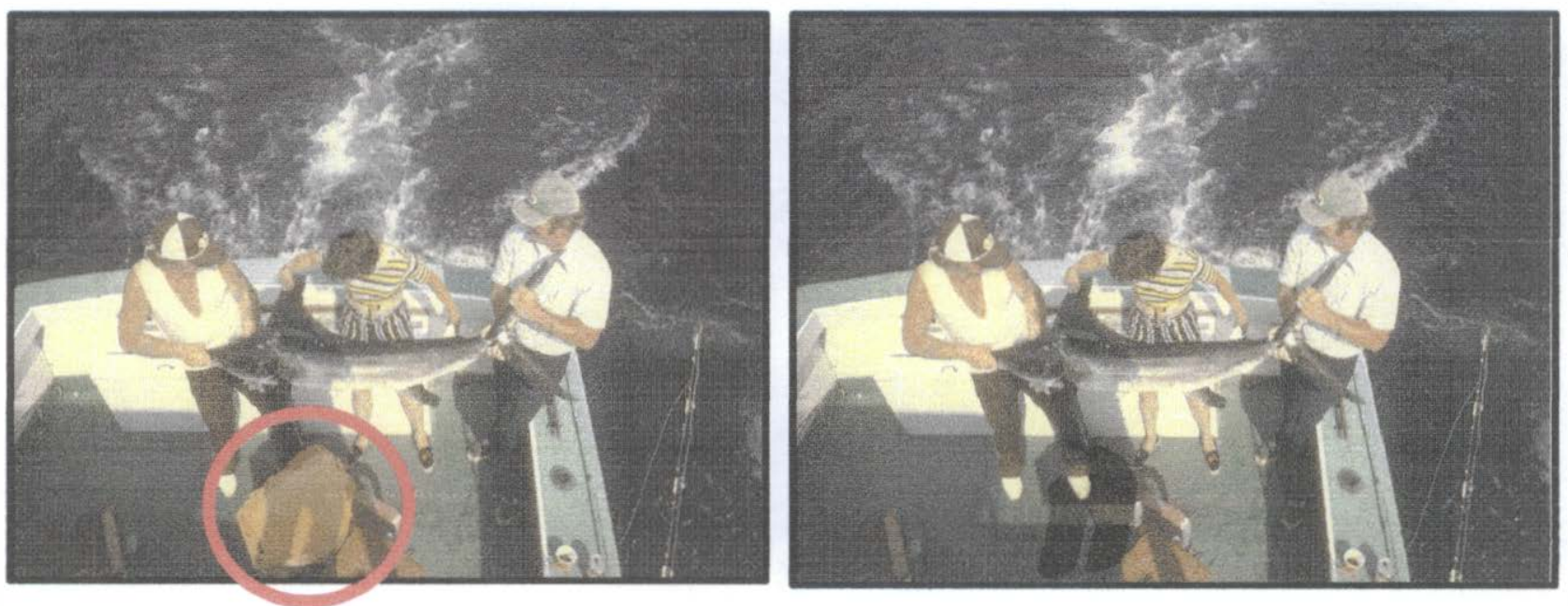


\section{Appendix D}

Non-critical trials viewed a total of 8 times, including one practice round.

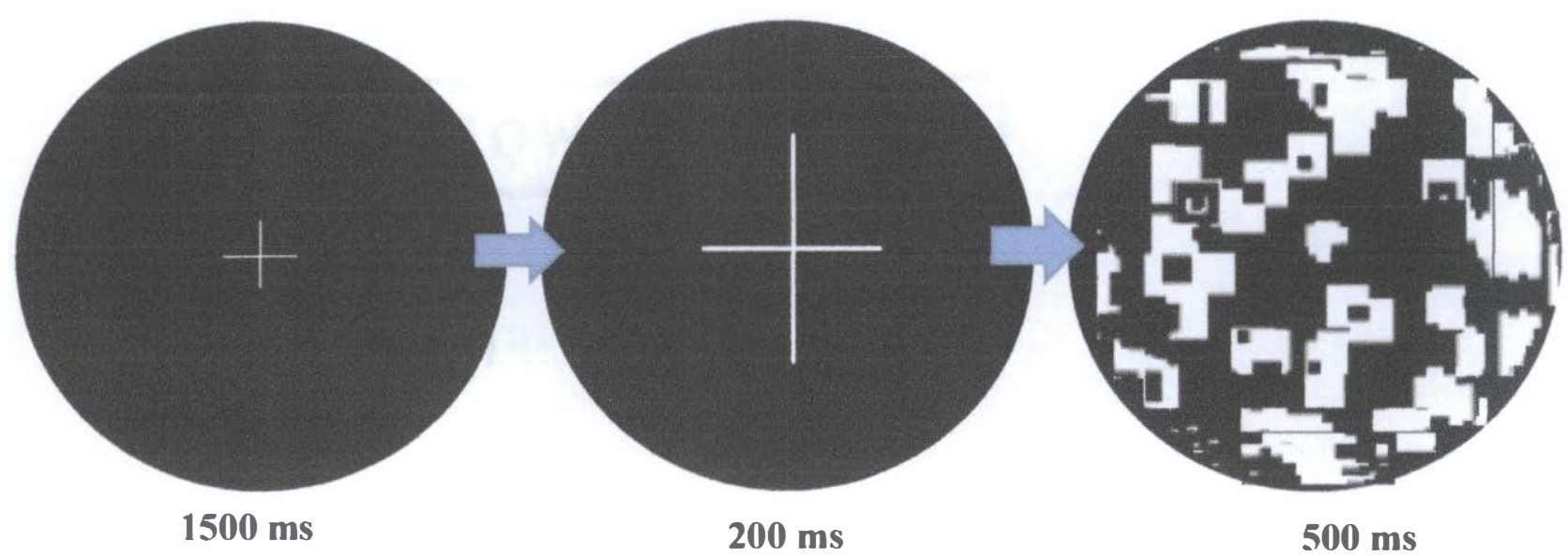

Critical trial, viewed only once.

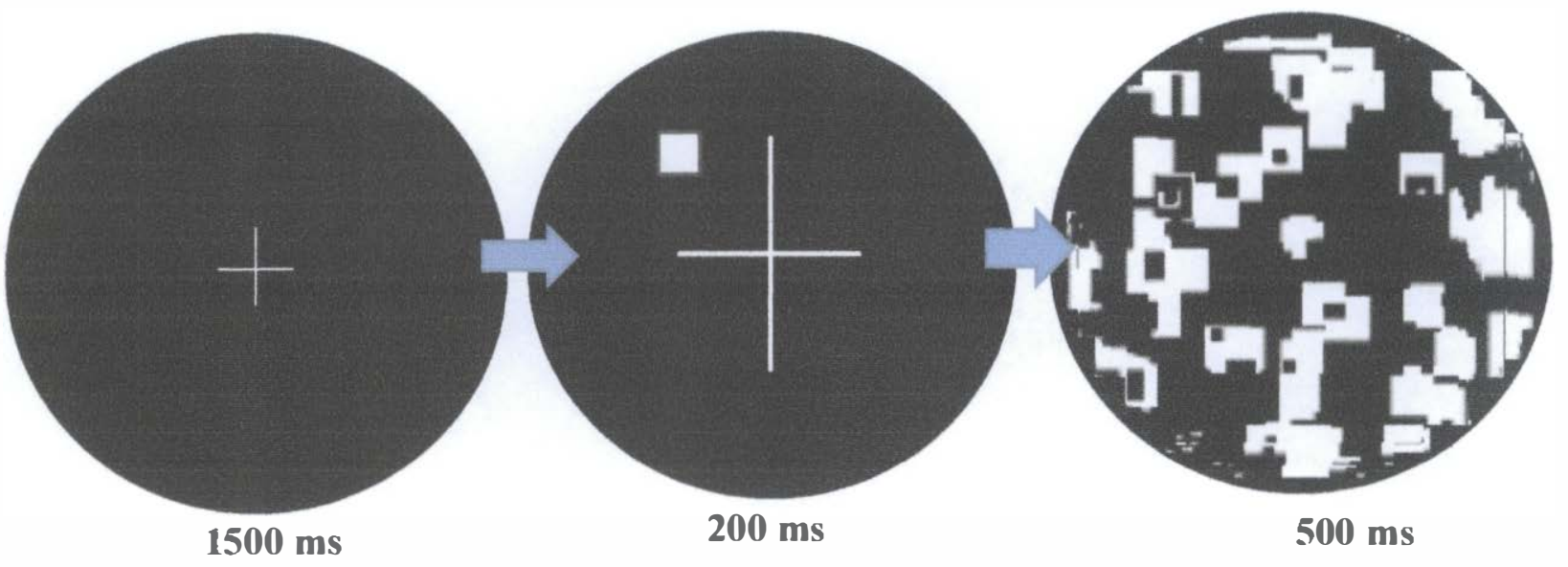




\section{Appendix E}

Participant \# \# of times restarted: Time to Completion:

\begin{tabular}{|c|c|c|c|}
\hline$\square 1020$ & 口 760 & $\square 500$ & $\square 240$ \\
\hline$\square 1007$ & $\square 747$ & $\square 487$ & $\square 227$ \\
\hline 口 994 & 口 734 & $\square 474$ & ㅁ 214 \\
\hline$\square 981$ & $\square 721$ & $\square 461$ & $\square 201$ \\
\hline 口 968 & $\square 708$ & $\square 448$ & $\square 188$ \\
\hline$\square 955$ & $\square 695$ & $\square 435$ & 175 \\
\hline 口 942 & $\square 682$ & $\square 422$ & ㅁ 162 \\
\hline$\square 929$ & $\square 669$ & $\square 409$ & $\square 149$ \\
\hline 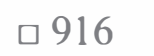 & $\square 656$ & $\square 396$ & $\square 136$ \\
\hline$\square 903$ & $\square 643$ & ㅁ 383 & $\square 123$ \\
\hline$\square 890$ & $\square 630$ & $\square 370$ & $\square 110$ \\
\hline$\square 877$ & $\square 617$ & $\square 357$ & $\square 97$ \\
\hline$\square 864$ & $\square 604$ & 344 & $\square 84$ \\
\hline$\square 851$ & 口 591 & 口 331 & 口 71 \\
\hline$\square 838$ & $\square 578$ & $\square 318$ & $\square 58$ \\
\hline$\square 825$ & 口 565 & 口 305 & $\square 45$ \\
\hline$\square 812$ & $\square 552$ & 口 292 & $\square 32$ \\
\hline 口 799 & 口 539 & $\square 279$ & $\square 19$ \\
\hline$\square 786$ & $\square 526$ & $\square 266$ & ㅁ 6 \\
\hline$\square 773$ & 口 513 & 253 & 口 -7 \\
\hline
\end{tabular}

